\title{
Radiation-induced neuropathies in head and neck cancer: prevention and treatment modalities
}

\author{
Patrick Azzam¹, Manal Mroueh ${ }^{1}$, Marina Francis ${ }^{1}$, Alaa Abou Daher ${ }^{1}$ and Youssef H Zeidan ${ }^{1,2}$ \\ ${ }^{1}$ Department of Anatomy, Cell Biology and Physiology, Faculty of Medicine, American University of Beirut, Beirut 1107 2020, Lebanon \\ ${ }^{2}$ Department of Radiation Oncology, American University of Beirut Medical Center, Beirut 1107 2020, Lebanon
}

\begin{abstract}
Head and neck cancer (HNC) is the sixth most common human malignancy with a global incidence of 650,000 cases per year. Radiotherapy (RT) is commonly used as an effective therapy to treat tumours as a definitive or adjuvant treatment. Despite the substantial advances in RT contouring and dosage delivery, patients suffer from various radiationinduced complications, among which are toxicities to the nervous tissues in the head and neck area. Radiation-mediated neuropathies manifest as a result of increased oxidative stress-mediated apoptosis, neuroinflammation and altered cellular function in the nervous tissues. Eventually, molecular damage results in the formation of fibrotic tissues leading to susceptible loss of function of numerous neuronal substructures. Neuropathic sequelae following irradiation in the head and neck area include sensorineural hearing loss, alterations in taste and smell functions along with brachial plexopathy, and cranial nerves palsies. Numerous management options are available to relieve radiationassociated neurotoxicities notwithstanding treatment alternatives that remain restricted with limited benefits. In the scope of this review, we discuss the use of variable management and therapeutic modalities to palliate common radiation-induced neuropathies in head and neck cancers.
\end{abstract}

Keywords: radiation, neuropathy, head and neck cancer, treatment, prevention

\section{Background}

Head and neck cancer (HNC) is the sixth most common human malignancy accounting for $3 \%$ of all cancers, with 650,000 cases and 330,000 deaths per year [1, 2]. HNC is a disease involving heterogeneous regions in the head and neck area such as the pharynx, larynx, paranasal sinus, nasal cavity, oral cavity and salivary glands. There are histopathological and molecular differences between these cancers, along with their treatment modalities and outcomes. About $90 \%$ of cases occurring in these anatomically complex regions are squamous cell carcinomas, which are diagnosed at a late stage when clinical symptoms arise. Tumorigenesis in HNC has genetic and environmental roots. Long-term tobacco and alcohol consumption along with high-risk types of human papillomavirus were found to be the main oncogenic risk factors.
Correspondence to: Youssef H Zeidan

Email:yz09@aub.edu.lb

ecancer 2020, 14:1133

https://doi.org/10.3332/ecancer.2020.1133

Published: 03/11/2020

Received: 16/05/2020

Publication costs for this article were supported by ecancer (UK Charity number 1176307).

Copyright: ( $\odot$ the authors; licensee ecancermedicalscience. This is an Open Access article distributed under the terms of the Creative Commons Attribution License (http:// creativecommons.org/licenses/by/3.0), which permits unrestricted use, distribution, and reproduction in any medium, provided the original work is properly cited. 
The treatment approaches of HNC involve surgery, radiotherapy (RT), chemotherapy, immunotherapy or combinational modalities. Around $80 \%$ of HNC patients undergo RT at least once during their course of the illness as primary or adjuvant treatment [3]. RT is known to inhibit the proliferation of tumour cells through different molecular mechanisms. Despite its effectiveness, radiation may induce collateral damage to neighbouring uninvolved normal tissues, exhibiting acute (weeks to months) or late (months to years) toxicities. The latter could severely impair patients' quality of life (QoL) and even worsen the prognosis. While RT has greatly evolved in the past couple of decades, no technology can completely protect healthy tissues from radiation damage. HNC patients still have to cope with treatment-related symptoms, despite increased survival owing to novel advanced treatment protocols and research.

Patients with HNC undergoing radiotherapy are at great risk of developing neuropathies due to the abundance of the nervous tissues in the head and neck region. Radiotherapy can have deleterious and detrimental damaging effects on the nervous system because of the limited capacity for repair and regeneration of the nervous tissues. While not as common as other adverse effects in HNC, neuropathies leave a longlasting compromise in the patients' well-being. Radiation-induced neuronal damage in HNC manifests mainly as sensorineural hearing loss (SNHL) and alterations in taste and smell sensory functions (dysgeusia and dysosmia, respectively). Injuries to the brachial plexus and cranial nerves were also reported, along with optical neuropathies and trouble in swallowing (dysphagia) and speaking (dysphonia). Understanding neuropathies emanating from HNC radiotherapy is essential for improving patients' quality of life, due to the irreversible nature of such injuries.

In this review, we discuss molecular mechanisms underlying radiation mediated neuropathies, followed by pathological aspects in head and neck cancer along with the available radioprotection and treatment methods.

\section{Molecular pathophysiology of radiation-induced neuronal injury}

Radiation-induced neuronal injury is a multifactorial pathogenesis with acute and long-term onsets. Acute symptoms like drowsiness, nausea and headaches are usually reversible and may resolve spontaneously. However, long-term side effects such as radionecrosis, white matter abnormalities and cognitive impairments are progressive and often permanent. Radiation-induced late brain injuries are irreversible changes that occur 6 months after radiotherapy, characterised by morphological damage as demyelination, gliosis and abnormal vascularisation [4]. Similarly, peripheral nerve radiation insult is defined by altered axonal growth along with perineurium formation $[5,6]$. On the cellular level, RT targets numerous molecular entities such as the integrity of the DNA molecule, oxidative stress, inflammatory cascades and synaptic activity. Ultimately, molecular damage leads to apoptosis, neuroinflammation and altered neuronal function, the main hallmarks of radiationinduced neuropathies in HNC.

\section{IR and neuronal apoptosis}

Neurons are differentiated postmitotic cells with reduced ability to repair radiation-mediated DNA damage. Consequently, a slow accumulation of radiation-induced DNA adducts in the neuronal genome leads to apoptosis [7]. Neuronal tissues are very heterogeneous due to differences in localisation, types of cells (neurons and neuroglia) and cell-cell interaction mechanisms. Thus, there is no homogenous response to ionising radiation, and neural substructures have large variabilities in molecular reaction.

Many studies have established that neuronal apoptosis is dose-dependent and occurs shortly after RT [8]. A dose of 2 Gy was able to induce apoptosis in postmitotic cortical neurons as early as 4 hours post-irradiation. Therefore, neurons were shown to be radiosensitive in contrast to astrocytes which remain radioresistant at $32 \mathrm{~Gy}$ [9]. Total dose administration and delivery methods were found to have an interesting impact on neurons' fate. For instance, fractionating the doses to allow DNA repair in between fractions proved to be a good strategy to reduce cell death in neurons [9]. Interestingly, a low dose of radiation (0.2 Gy) did not affect whatsoever reactive oxygen species (ROS) levels or neuronal synapses. Such low doses result in mitochondrial fusion and the expression of complexes I and III, promoting an adaptive cellular mechanism rather than cell death [10].

The key behind neuronal death is indeed direct or indirect radiation-induced ROS upregulation. Modulating oxidative stress levels by administration of free radicals scavengers as melatonin, rhubarb and kukoamine rescued neurons from radiation-mediated apoptosis [1113]. In addition, tetracyclines derivates and ceftriaxone relieved neurons from oxidative stress and subsequent apoptosis [14]. Irradiated 
cell-conditioned medium culture promoted oxidative stress and cell death, which were alleviated if neurons were co-cultured with glial cells [15-17]. Furthermore, metallothionein protected neurons and astrocytes from ionising radiation potentially through an antioxidant mechanism [18]. Thus, promoting free radical scavenging rescued neurons from cell death post-irradiation.

Radiation-induced apoptosis was found to be p53-, Bax- and ATM-dependent in most neuronal structures, while the role of caspase-3 remains unclear [19-23]. Similarly, cell death in glial structures was found to be p53-dependent [24]. In sensory ganglion rat cells, the ATM/ p53 pathway did not induce apoptosis but mediated neuronal entry into the G0-G1 transition phase by increasing p21 and cyclin-D [25]. Calcium ions were also shown to modulate RT-induced cell death in immature dorsal ganglion root [26, 27]. Whether calcium ions rescue neurons by abrogating p53-dependent apoptosis remains to be elucidated. On another note, multiple studies suggest the implication of c-Jun in radiation-induced apoptosis of different neuronal substructures [28, 29].

Targeting apoptosis-related pathways could be a therapeutic modality in rescuing neurons from RT-induced death. For instance, minocycline via its targeting to AMPKa1 inhibited neuronal apoptosis by promoting autophagy [14,30]. Similarly, administration of GSK3ß and MDM2 inhibitors suppressed p53 accumulation and halted radiation-mediated cell death in hippocampal HT-22 cells [31]. Furthermore, NFAT3/c4 inhibition halted excitotoxicity induced apoptosis after radiation exposure in hippocampal neurons [32].

\section{IR and neuroinflammation}

The main hallmark for neuroinflammation is the occurrence of radiation-induced fibrosis (RIF) which is a late, unavoidable complication of radiation injury. RIF occurs between 4 and 12 months after therapy, and its pathogenesis is well established. Following injury and apoptosis, tissues secrete chemoattractants known as proinflammatory cytokines, such as TNFa, IL-1B, COX2 and AP-1 [8, 33]. These molecules activate nonspecific inflammatory cascades and promote neutrophils and monocytes recruitment to the site of injury. In such circumstances, neutrophils are engaged via increased ICAM-1 (Intercellular Adhesion Molecule 1) and PECAM-1 (Platelet endothelial cell adhesion molecule-1) expression on endothelial cells [4, 34]. In fact, nerve injury to the lumbar root in rats increases ICAM-1 and PECAM-1 immunoreactivity along with the invasion of lymphocytes into the spinal parenchyma [35]. Afterwards, monocytes are transformed into PDGF (Platelet-derived growth factor) secreting M2-macrophages, promoting the recruitment of stromal fibroblasts along with the differentiation of circulating mesenchymal cells. Through TGF- $\beta$ (Transforming growth factor beta) secreted by M2-macrophages, stromal fibroblasts are differentiated into myofibroblasts that produce a surplus of extracellular matrix components such as collagen, along with inhibition of extracellular matrix-degrading enzymes. Thus, fibrotic areas are generated, leading to susceptible loss of function or even tissue atrophy [36].

A similar mechanism is initiated in the central nervous system where along with lymphocytes recruitment, there is an activation of microglia. This process acts through the NF-kb pathway coupled with the upregulation of microglial MHC and CD68. Injured neurons contribute to the inflammatory process by secreting HMGB1 (High mobility group box 1 ) and calreticulin which are ligands to microglia, thus promoting phagocytosis of both damaged and healthy neurons. This phenomenon is accompanied by the recruitment of peripheral macrophages through CCL2-CCR2 chemoattraction [4]. Eventually, persistent microglial activation will lead to amplified neuronal damage in the long term [8, 37]. Managing chronic neuroinflammation could alleviate a substantial part of the neuropathies observed following RT.

Peripheral nerves display electrophysiological changes in early phases of RIF pathogenesis. The pathological process includes axonal injury and demyelination, followed by a pronounced fibrotic tissue around nerve trunks and decreased vascular supply. Many risk factors can lead to such damage including a large total dose (>50 Gy to plexus, >60 Gy to cranial nerves), a large dose per fraction > $2.5 \mathrm{~Gy}$, a considerable radiation field where nerve fibres are included and patients' comorbidities [34].

\section{IR and alterations in neuronal function}

While neurons can withstand small doses of radiation [10], acute and long-term morphological and electrophysiological changes occur in neuronal tissues with large doses. In fact, intrinsic neuronal membrane alterations were noted 3 months after exposure, hinting a long-term effect of radiation [38]. Dendritic architecture is compromised following a $10 \mathrm{~Gy}$ irradiation in hippocampal neurons, marked by a decrease in 
branching, length and density of dendritic spines, along with changes in synaptic protein levels [39]. Changes in synaptic transmission were recorded in the CA1 region of the hippocampus after radiation, characterised by the downregulation of spike generation, excitability and synaptic efficacy. Furthermore, radiation exposure resulted in an acute decline in excitatory NMDAR (N-methyl-D-aspartate receptor) receptors with a concurrent increase of inhibitory GABA ( $\gamma$-aminobutyric acid) receptors corresponding with suppressed long-term potentiation (LTP) [40]. In addition, radiation suppressed the expression of Arc, an essential protein in sustaining LTP and spatial memory consolidation [41]. Conversely, some studies mentioned a dramatic increase in synaptic activity after irradiation leading to neuronal excitotoxicity [32]. Intriguingly, low doses of radiation (0.1-0.5 Gy) increased synaptic excitability along with dendritic spines and neural outgrowth coupled to a reduced mitochondrial function $[42,43]$. There is also growing evidence that low radiation dose confers to neurons a radioadaptive mechanism manifested in an upregulation of antioxidant enzymes and anti-inflammatory cytokines [44].

Overall, unattended imbalance in ROS levels due to radiation exposure may be behind the observed 'domino effect' in these neuropathies. From apoptosis to radiation-induced fibrosis, and impaired neuronal function, this pathological cascade needs to be halted in its earliest stages for patients to have better survival chances.

\section{Sensory dysfunctions and radioprotection}

Head and neck cancer radiation-induced neuropathies can affect fundamental sensory functions. This can manifest as hearing loss/decline, taste and smell alterations, along with different neuropathies involving the brachial plexus and cranial nerves. Thus, it is of utmost importance to address these issues in preclinical experiments in order to tackle the pathological mechanisms and develop curative strategies.

\section{Sensorineural hearing loss}

Sensorineural hearing loss is a common neurological complication that emerges following radiotherapy in HNC patients. A higher risk of developing SNHL is noted when the inner cochlea is within the radiation field of primary tumour sites [45]. Auditory organs that are most affected by radiation injury are the stria vascularis and organ of Corti of the cochlea. Following irradiation, recruitment of macrophages and inflammatory cells is ensured by the stria vascularis, thus triggering inflammation and ROS imbalance in the auditory milieu. This promotes chronic injury to the auditory pathway manifested in p53-dependent apoptosis of the outer and inner auditory hair cells [46]. Therefore, radiation-induced auditory insult manifests as hearing loss/decline, potential ossification of the inner ear fluid space and even inflammationmediated oedema in the cochlear nerve [47]. Para-cochlear structures as the spiral ganglion neurons may also be injured, resulting in abnormal auditory brainstem responses (ABR) [46].

High-frequency hearing (above $4 \mathrm{kHz}$ ) was mainly affected in HNC patients receiving radiotherapy, whereas speech frequency (below 4 $\mathrm{kHz}$ ) was less damaged. Incidence of SHNL increased progressively with time and was found to be dose-dependent and permanent [46]. A randomised prospective trial, including 110 patients noted no significant differences in cochlear sparing between conventional radiotherapy and intensity-modulated radiotherapy (IMRT). IMRT is an advanced technology that conforms radiation dose to the shape of the tumour, thereby sparing normal tissues from radiation [48]. Both groups had hearing loss superior to $10 \mathrm{db}$, while no discrepancies were found in balance assessment, ototoxicity, QoL and progressive hearing impairment. These results could be explained by the considerable number of patients who withdrew from the study leading to a reduction in its statistical power [49]. Another suggestion could be the radiosensitivity of the auditory apparatus regardless of the treatment technique received by patients.

Many experimental studies have been conducted in vitro and in vivo, to develop pharmacological drugs against radiation-induced ototoxicity. However, pharmacological agents have rarely been tested in clinical trials. ROS scavenging agents were found to have a radioprotective role in the auditory milieu. For instance, L-N-Acetylcysteine was shown to protect OC-k38 auditory hair cell line by promoting survival and inhibiting apoptosis 72 hours after irradiation [50]. In addition, aminothiol prc-210 alleviated inflammation and spinal ganglion injury in guinea pigs and consequently promoted better ABR responses in comparison with the control group [51]. Similarly, the synthetic steroid dexamethasone protected organ of Corti rat explants from irradiation as it reduced the levels of oxidative stress and apoptosis in a dose-dependent manner [52].

Other agents have been investigated for radioprotection in the auditory system outside the oxidative stress context. Epicatechin, a green tea extract component, abrogated apoptosis and preserved mitochondrial membrane potential after radiation exposure in HEI-OC1 and 
UB-OC1 cell lines by targeting the JUN and ERK pathways [53]. Piracetam, a derivative of gamma-aminobutyric acid, was found to abrogate the degeneration of the spinal ganglion, stria vascularis and outer auditory hair cell in a fractionated irradiation guinea pig model [54]. The role of metformin was also investigated in radiation-induced hearing impairment; however, no otoprotective role was elucidated for the drug [55]. Alternatively, miRNA-207 stood out as a microRNA key player in radiation-induced damage in HEI-OC1 cell line following microarray analysis [56].

Sensorineural hearing loss is further exacerbated in patients receiving chemoradiotherapy, specifically with concomitant administration of cisplatin, a well-known ototoxic agent $[57,58]$. Much experimental data regarding treatment-related hearing impairment have been obtained from chemoradiation or chemotherapy-induced ototoxicity, in contrast with those who used ionising radiation solely. SNHL was found to be cisplatin and radiation dose-dependent and was associated with age, tobacco and alcohol consumption [59, 60]. Combined treatment of radiation and cisplatin resulted in worse hearing thresholds compared to subjects treated to radiation alone [61]. A well-established ROS scavenger, amifostine, had disputable results regarding cisplatin mediated hearing loss and had neurotoxic side effects on its own [57, 58, 62-64]. Numerous agents have been proven effective in alleviating cisplatin-induced ototoxicity. These include agents as $\mathrm{N}$-acetylcysteine, sodium thiosulphate, D-methionine, lipoic acid, ebselen, diethyldithiocarbamate, 4-methylthiobenzoic acid, sodium salicylate, neurotrophin-3, BDNF (Brain-derived neurotrophic factor), flunarizine and NOX3 RNA silencing [57, 65]. Under basal conditions, Nfatc4 double knockout mice abrogated TNF-mediated apoptosis in auditory hair cells [66]. In a sudden loss of sensorineural hearing loss, intratympanic or oral administration of steroids was effective in auditory recovery [67]. All of the previously mentioned drugs should be investigated in a radiation context in $\mathrm{HNC}$ under clinical trials.

As for non-pharmacological modalities, cochlear implantations were successful in recuperating hearing post-treatment [68]. This finding elicits that some auditory nerve fibres can survive radiotherapy, albeit the extensive damage that radiation exerts on the central hearing pathway and acoustic nerves. On another note, it remains unclear if hyperbaric oxygen treatment (HBOT) could be effective in retrieving hearing sense. While it has been not effective in mild auditory impairment, HBOT might contribute to hearing improvement as a part of a multidisciplinary approach in patients with severe SNHL [69].

\section{Dysgeusia}

Similar to SNHL, dysgeusia or taste alteration is a common side effect observed in patients with HNC undergoing radiotherapy. Taste distortion is usually a complication associated with xerostomia (dry mouth), another radiation-induced side effect in HNC. Hyposalivation was suggested to be the main reason behind the loss of gustatory abilities; however, research showed that abnormalities in taste have alternative pathophysiological aspects.

Flavours are detected via taste buds localised in the tongue, which are neuroepithelial cells innervated by the glossopharyngeal IX and facial VII nerves. Gustatory messages are then transmitted to the brain stem, specifically to the rostral solitary nucleus, and further delivered to the primary gustatory cortex. There are five basic tastes (sour, salty, sweet, bitter and savoury umami) that are sensed with the evolutionary purposes of pleasure/survival (sweet, umami and salty) and defence (sour, bitter) [70]. Alteration in taste influences food intake, nutritional profile and subsequently patients' quality of life that could generate additional unwanted complications.

Radiation-induced dysgeusia in HNC had a predominant incidence rate of 69\%-93\% [71-74]. Bitter and salty tastes were the most affected after irradiation [71, 75], while the sweet taste was the least endangered [74]. Sour taste loss is more common in patients undergoing direct oral cavity radiotherapy [76]. Nevertheless, there are many discrepancies through literature regarding which flavour sensing is the most affected by radiation. The observed disparities are due to variables that differed between studies such as radiation dose, cancer type and whether subjective questionnaires or objective methods were used to assess gustatory abilities [77]. A maximum manifestation of dysgeusia was observed at a dose of 40-60 Gy to the tongue area [78]. Taste impairments start at 5 weeks post-irradiation, followed by partial recovery at 6 months. Nonetheless, partial loss of taste was still noted at 2 years post-radiotherapy [78, 79]. Dysgeusia improved between 1 and 12 months and was dependent on the dose to the oral cavity and tongue [80]. Recovery time post-treatment varied with respect to tastes through literature, but the sweet flavour was the quickest to recover [79]. Furthermore, no differences in dysgeusia prevalence were noted between hyperfractionated and conventional radiotherapy [81], while IMRT was advantageous in QoL outcome [82]. An ongoing clinical trial in Royal Marsden Hospital is correlating qualitative and quantitative data for taste loss with mean of radiation doses to the oral cavity and salivary glands using detailed dosimetric data [83]. 
Experimental studies were developed to investigate the mechanisms behind radiation-induced dysgeusia in vivo. Most studies focused on the proliferation of taste bud cells. Irradiated mice showed an increase in sucrose threshold compared to control, which could be explained by the inhibition of taste bud cells' proliferation, particularly type II cells detecting sweet flavours [84]. A pivotal molecular study established that the downregulation of genes in the Wnt/ $\beta$-catenin pathway-repressed taste buds proliferation after fractionated irradiation, mimicking treatment for HNC patients [85]. Following RT, a chain of molecular events unfolds in taste buds, starting with apoptosis (1 day), cell cycle arrest (1-3 days), entry into $S$ and $M$ phases (5-6 days) and a reduction of differentiated taste bud cells ( 7 days). The established timeline shows the sudden temporary interruption of cell proliferation post-irradiation, which is resumed around one week later [86]. Furthermore, inhibition of protein deacetylase SIRT1 in taste buds organoids promoted survival after irradiation [87]. Similarly, genetic loss of the tumour suppressor protein CHK2 was found to partially abrogate p53-mediated apoptosis of taste cells [88].

Very few drugs have been developed to mitigate radiation-induced taste alterations. Zinc sulphate was investigated in this regard, with studies reporting contradictory results. Zinc is an essential nutrient with antioxidants properties and a cofactor for many enzymes present in the taste buds. It also promotes gustin synthesis, a protein essential for the regeneration and proliferation of taste buds.

A randomised trial claimed that the administration of zinc supplements improved patients' gustatory abilities one-month post-radiotherapy [89]. On the other hand, a study noted no difference in recovery between zinc treated and placebo groups [90]. The latter was supported by another clinical trial in which zinc sulphate failed to prevent radiation-induced dysgeusia [91]. A recent clinical trial completed in 2019 in Dow University aims to further examine the role of zinc in radiation-induced dysgeusia. However, no results have emerged from this study yet [92]. Amifostine fell short in relieving taste alterations following RT, which were surprisingly more common in the agent-treated arm compared to control in one study [93].

Medicinal herbs were also considered for treating taste alterations. Prophylactic intravenous administration of mint oil, Mint spicata, preradiation was found to alleviate taste aversion in rats [94]. Similar results have been uncovered with intravenous administration of a ginger extract Zingiber officinale that was found to reduce lipid peroxidation and increase superoxide anion scavenging [95].

\section{Dysosmia}

Radiation-induced olfactory dysfunctions in patients with head and neck cancer remain poorly studied. This can be attributed to (1) the rare occurrence of nasal cavity and paranasal tumours (3\% of HNC malignancies) [96], (2) the upper anatomical localisation of the olfactory milieu which is spared from radiation injury when patients are treated for the more common $\mathrm{HNC}(3)$ and the quick regeneration of the olfactory neuroepithelium compared to other tissues [97]. Nevertheless, dysosmia is still a side effect that impacts survivors' day-to-day life, from food intake, well-being and inability to detect safety hazard situations [98].

A systematic review reported that odour detection and identification thresholds were impaired right after radiotherapy completion and were further exacerbated if patients had concurrent chemotherapy. Recovery of odour perception was reported as early as 6 months posttreatment. Olfactory recuperation was further prolonged up to 20 months if patients received a dose higher than 10 Gy to the olfactory epithelium. Olfactory alterations were reported as far as 5 years post-radiotherapy. Although odour detection was heavily affected, smell identification was less influenced by treatment. A study reported no effect on olfactory identification threshold up to 5 years post-radiotherapy [99]. Similar to dysgeusia, the paucity of subjective and objective assessment hinders the ability to measure smell alterations [77].

Besides its direct effects on the olfactory epithelium, radiation also impacts the nasal cavity environment. Exposure to X-rays increased nasal irrigation and obstruction along with hyposmia in patients subjected to chemoradiation, with no differences reported between conventional radiotherapy and IMRT [100]. Moreover, IMRT increased the incidence of olfactory alterations and rhinosinusitis in patients with nasopharyngeal cancer [101], which was found to be associated with the extent of the tumour and nasal irrigation [102].

The aetiology of radiation-induced dysosmia has been poorly examined. One study investigated the morphological changes in olfactory neuroepithelium following radiation in adult mice. The proliferation of the olfactory stem cells has been inhibited as early as 2 hours postirradiation, completely abolished at 24 hours and recovered 5 weeks later. Layers of the olfactory epithelium are also affected by radiation, with the cessation of mitosis, especially in the basal lamina. Interestingly, no differences regarding apoptosis were noted in the olfactory 
epithelium between the irradiated and control groups [103]. A reduction in neurogenesis and size of the olfactory bulb was revealed 15 days post-irradiation. This depletion was marked by a decrease in BrdU-positive cells in the glomerular and intralaminar layers, remaining unchanged up to 60 days after irradiation. Changes in the subtypes of the interneurons connecting the olfactory epithelium to the olfactory bulb were also noted, with a marked decrease of GABA-ergic subtype [104].

No radioprotective agents against dysosmia have been adopted. However, one clinical trial at Stanford University was launched in 2017 to study the effect of olfactory training in improving smell perception in patients with nasopharyngeal and paranasal sinus cancers after radiotherapy. No results have been reported from this study to date [105]. Prior studies established that olfactory training improves patients' sense of smell over time [106-108]. For instance, exposure to 4 different odours twice a day over 8 months in patients with smell disorders enhanced olfactory function, especially in those treated with concurrent corticosteroids [106].

There are limited treatments available to ameliorate smell alterations regardless of the underlying aetiology. Nasal occlusions, topical nasal saline and oxymetazoline $\mathrm{HCl}$ drops have been proposed for patients experiencing dreadful smelling (phantosmia) to reduce their odour perception. Sedatives, anti-depressants and anti-epileptic drugs have been suggested in blocking the olfactory function in patients experiencing phantosmia. However, all the abovementioned lack testing in clinical trials and may exert severe unwanted side effects. Topical cocaine drops have been advocated for anaesthetising olfactory neurons but may exhibit undesired effects [109]. In addition, short-term systematic administration of corticosteroids was proposed for sinonasal smell disorders [110], along with acupuncture [111, 112], transcranial magnetic stimulation [113], caroverine [114], pentoxyphilline [115], theophylline [116], vitamin A [117], lipoic acid [118] and minocycline [119]. The role of oral zinc administration was also examined, where it was found to have regenerative properties in post-traumatic olfactory disorders [120]. Furthermore, radical and invasive solutions as surgery have been adopted. Surgical treatments are effective in annihilating connections between the olfactory bulb and the olfactory neuroepithelium to halt phantosmia. While this method treats the symptoms, it leaves the patient with permanent smelling loss or anosmia [109]. Further studies are warranted in managing radiation-induced dysosmia taking advantage of previously established treatments for smell disorders.

\section{Brachial plexopathies and cranial neuropathies}

Brachial plexopathies and cranial neuropathies are among the late neurological complications emanating from radiotherapy in patients with $\mathrm{HNC}$. Both entities manifest as radiation insult to neuronal tissues close to or within the radiation field. Intermittent and continuous neuropathies have been reported by patients with HNC undergoing radiotherapy. Neuronal pain was mainly identified in the head and oral cavity regions, followed by the shoulder and arm areas [121].

Radiation-induced peripheral neuropathies (RIPN) are first characterised by a change in neurons' electrophysiological state. Depending on many variables, such as radiation dose, neuronal tissues involved, physiological conditions of the patient, RIPN may resolve spontaneously or worsen over several years. Following disruption in homeostasis, inflammation-mediated fibrosis may develop, leading to a fibroatrophic state with poor vascularisation and entrapment of nerve bundles. This process is orchestrated by a dramatic increase in oxidative stress along with amplified signalling of inflammatory cytokines. Neuroinflammation is stimulated as a consequence of lysosomal digestion of necrotic neural tissues by neighbouring cells [34, 122].

Brachial plexus is defined as a network of nerves emerging from the upper cervical and thoracic part of the spinal cord. It is responsible for the muscular, cutaneous and motor-sensory innervation of the shoulder, chest and upper extremity. Thereby, injury to this plexus known as radiation-induced brachial plexopathy (RIBP) could affect patients' motor and sensory activities, along with pain, weakness and paralysis in severe cases. Current literature investigating plexopathies and neuropathies following irradiation comes mostly from case reports.

Injury of the brachial plexus was reported in $22 \%$ of patients who had received radiotherapy for HNC either post-operatively, definitively or in combination with chemotherapy. The most prevalent symptom reported was ipsilateral pain (50\%), followed by numbness or tingling feeling known as paraesthesia (40\%) and motor weakness or muscle atrophy (25\%) [123]. However, contradictory results were reported regarding the tolerance dose of the brachial plexus. In fact, some reported no brachial plexopathies in $72 \%$ of patients receiving a dose superior to $60 \mathrm{~Gy}$ [124]. Moreover, only $2 \%$ of patients reported early transient radiation-induced brachial plexopathy after the seventh and eighth months of follow-up [125]. In addition, the therapeutic dose was neither a risk factor for brachial plexopathy in sequential IMRT [126]. While 
a systemic meta-analysis reported a low percentage of RIPB incidence in most cohort studies, it supported the association between increasing dose and the occurrence of the injury [127]. Therefore, the radiation dose and mode of delivery may be implicated in RIBP.

Radiation-induced cranial neuropathy (RICN) has been investigated as a complication following treatment in HNC. There are many discrepancies regarding the incidence rate of this injury, with some defining it as a rare outcome [128-131], while others supporting it as a more frequent one [132-134]. The inconsistencies could be explained by differences in follow-up periods with a higher incidence reported with longer follow up. In a cross-sectional study involving 317 nasopharyngeal cancer patients, 30.9\% developed cranial nerve injury, more frequently in lower nerves (25.5\%) compared to the upper ones (13.9\%). The cumulative incidence of cranial nerve insult reached its highest at 20 years post-radiotherapy (44.5\%). Overall, radiation-induced cranial nerve palsy correlated with a total dose of radiation along with chemotherapy, upper neck fibrosis and longer duration of therapy [135, 136]. Lower cranial nerves that are most vulnerable to treatment are the glossopharyngeal IX, vagus X and the hypoglossal XII [128, 133, 135]. Clinically, such injuries manifest in difficulties in speech (dysphonia), swallowing (dysphagia) and chewing (discussed further below). Upper cranial nerves are affected to a lesser extent. As a consequence, patients displayed asymmetry of facial sensitivity, facial weakness, abnormalities in eye movement or vision due to palsies in the trigeminal V, abducens VI and facial VII nerves [128, 134, 136].

Contouring both the brachial and cranial nerve bundles is used as a first-line in the prevention of both RIBP and RICN. Delineation using computed-tomography (CT) helps in localising neural tissues and subsequent sparing from radiation [137]. A combination of both magnetic resonance imaging and CT techniques leads to better contouring, as suggested for the brachial plexus [138] and the cranial nerves [139]. Radiation oncologists usually outline the brachial plexus as organ-at-risk (OAR) following consensus guidelines and contouring atlases [137]. Many guidelines have also been developed for various cranial nerves, especially for the $\mathrm{V}$ and IX through XII nerves as those are the most vulnerable to radiation injury $[140,141]$. Although contouring nerves is essential, some cases require reducing the total dose, dose per fraction or field size to limit neuropathic collateral damage.

While management of RIBP and RICP mainly focuses on treating the symptoms such as neuropathic pain, motor and sensory weakness, a curative strategy has yet to be established. Incidentally, numerous ongoing clinical trials are focusing on managing RIPN [142-144]. To alleviate neuroinflammation, NSAIDs are used as first-line treatment, followed by the temporary use of corticosteroids due to potential side effects [145]. The use of prednisone and methylprednisone for radiation-induced neuropathic pain in HNC is the subject of a current clinical trial in MD Anderson Cancer Center [143]. Neuropathic pain is usually symptomatically treated by opioids; however, the use of anti-epileptic drugs (gabapentin) and tricyclic anti-depressants (amitryptiline) has been suggested [34, 146]. A clinical trial in Belgium will investigate further the use of gabapentin as an alternative to opioids for neuropathic pain after radiotherapy in HNC [144]. Furthermore, a randomised clinical trial showed the effectiveness of another anti-convulsant, pregabalin, in treating radiation-induced neuropathic pain in HNC patients. The administration of the anti-epileptic drug showed improvement in QoL of patients despite the manifestation of some adverse effects [147]. Apatinib, a selective tyrosine kinase inhibitor for VEGF-2, is another agent under clinical study in China in patients with radiation-induced brain injury [142]. Contrastingly, no sufficient evidence supports the use of HBOT in easing RIBP [148]. On that note, a combinational administration of pentoxyphilline-tocopherol-clodronate did not elucidate any beneficial effect in RIBP, albeit the promising effects of these drugs in other radiation-induced side effects in HNC demonstrated by the same group [149].

More severe cases may require surgical interventions as neurolysis, nerve grafting or removal of fibrotic tissue. Neurolysis may improve nerve conduction by degenerating specific targeted groups of neurons responsible for the pain manifestation. Nerve graft and neurotisation are procedures used to treat clean-cut injuries with a proximal stump available for grafting, usually done in brachial plexopathies [146]. Moreover, the physical release of entrapped nerve bundles from excessive fibrotic tissues may improve symptoms in late stages of nerve fibrosis. Nevertheless, large clinical studies are needed to determine the effectiveness of such invasive treatments, as to date, they do not deliver satisfactory results [150].

\section{Optic neuropathies}

Optic neuropathies are potential neurologic sequelae of RT in HNC. Radiation-induced optic neuropathy (RION) is defined as an irreversible, progressive-to-abrupt ipsilateral or bilateral visual loss, months to years following irradiation. Onset culminates at 1-2.5 years [151, 152] and ranges from 10 to 58 months post-RT [153, 154]. Usually painless, RION is an uncommon side effect with an early incidence of $9 \%-11 \%$ 
which may rise up to $20 \%$ at 5-10 years following treatment [153-155]. Skull-base malignancies along with paraorbital and paranasal tumours place the anterior visual pathways, optic nerves and chiasm at risk of injury due to their proximity to treated fields.

Pathophysiological mechanisms underlying optic neuropathies are not clear. Limited evidence suggests that the main aetiology behind RION is damage to the capillary endothelium, leading to ischemic demyelination and reactive astrocytosis [156]. In a similar fashion, radiationinduced retinopathy (RIR) is postulated to be caused by injury to the vascular endothelial cells of the retina leading to occlusive retinovasculopathy [151]. In addition, direct neuronal injury to the retina and optic nerves has also been proposed. Moreover, radiation may cause regional alterations in retinal oxygen delivery and/or metabolism [157]. Molecularly, retinal apoptosis was found to be ATM and p53-dependent in rats [158]. Treatment with ramipril, an ACE agonist, 2 weeks post-radiation mitigated RION by restoring normal visual evoked potential in vivo [159]. Insufficient levels of axonal transport motor proteins as dynein-1, kinesin-1 and kinesin-2 were reported in rats following a dose of $20 \mathrm{~Gy}$, while no differences were found in a-tubulin, $\beta$-tubulin and SMI31 levels [160].

To date, no treatment is available to alleviate or restore visual function once visual impairment has begun. Given the rarity of RION and RIR, few therapeutic modalities have been investigated outside case report studies. Bevacizumab, an anti-vascular endothelial growth factor, improved resolution of optic disk oedema and vision, reducing papillary haemorrhages in 64\% of RION patients [161, 162]. Bevacizumab proved to be effective in treating optic neuropathies outside the RT context [163]. Conversely, HBOT and oral corticosteroids were unsuccessful in ameliorating impaired vision [156, 164, 165] in contrast to one case report [166]. Discrepancies in overall treatment time with HBOT, its initiation after RT and the severity of visual acuity could explain the inconsistency of the results. Overall, very shy data support the use of HBOT in treating RION.

A combination of bevacizumab, pentoxifylline and dexamethasone was efficacious in a case report [167]. Others described a dramatic improvement in a patient's vision treated with pentoxifylline, vitamin E and dexamethasone [168]. Pentoxifylline alone enhanced RIR in another case report [169]. This improvement might be due to the ability of pentoxifylline to increase blood flow and flexibility of erythrocytes and leukocytes. Larger clinical studies are warranted to solidify the potential therapeutic effect of these combinational treatments. Similarly, anti-coagulants such as heparin and warfarin have been suggested to treat RION. While these agents were potent in treating other neuronal injuries related to radiation, anti-coagulants failed in ameliorating RION [170].

\section{Dysphagia and dysphonia}

Swallowing and speech impairments are common during RT for HNC patients. While such complications are usually transient, they can persist, leading to chronic dysphagia and dysphonia that impact patients' QoL [171]. Normal swallowing is orchestrated by multiple cranial nerves in addition to a central pattern generator located in the medulla. Deglutition allows the food bolus to pass from the oral cavity to the pharynx (Vth, VIIth and XIIth cranial nerves) while shielding the larynx (involuntary, through the IXth and Xth cranial nerves) and into the oesophagus hereafter [172]. Disordered swallowing leads to aspiration and in severe cases to pneumonia [173]. Pathophysiological mechanisms behind these impairments are mostly due to radiation-mediated fibrosis and oedema that compromise the muscular activity of the larynx and pharynx. In fact, silent aspiration is frequent in irradiated HNC patients due to an ineffective or even absent cough reflex [173, 174].

The main culprit behind the fibrotic aspect of dysphagia is TGFß. Through a well-orchestrated repertoire of inflammatory cell signalling cascades, TGFß's activation leads to the increased deposition of collagen compromising pharyngolaryngeal structures and reducing muscular motility [171, 174-176]. Alternatively, peripheral and cranial nerves that innervate the swallowing musculature are at risk of radiation damage and could trigger the neurogenic root of dysphagia.

The incidence of dysphagia varies from $15 \%$ to $55 \%[171,172,175,177]$. This broad range could be explained by the different subjective and objective assessment methods. Dysphagia is frequently underreported by either patients or physicians [175, 178]. Furthermore, the scarcity of total dose, dose per fraction and interfraction interval, and the proximity of treated fields to the pharyngolaryngeal area, contribute in extending the incidence range $[171,175]$. Moreover, increased age, smoking, prophylactic feeding tubes and surgical interventions make excellent predictors for late dysphagia [173, 175]. According to a meta-analysis, swallowing problems peak at 0-3 months after RT (acute dysphagia) and usually improve at 6-12 months after the treatment [173, 179]. Chronic dysphagia could occur 1-year post-RT if there is no improvement in swallowing activity. A dose of $>41$ Gy with $>24 \%$ volume of the irradiated larynx was associated with an increased risk of aspiration and percutaneous 
endoscopic gastrostomy dependency [179]. Radiation to critical key structures such as the cricopharyngeal muscle and cervical oesophagus might have a role in acute dysphagia [180]. Late dysphagia was associated with the glottic, supraglottic larynx and pharyngeal constrictors [178, 181, 182]. IMRT succeeded in limiting radiated volumes to these areas and therefore reduced aspiration risks [181, 182].

Treatment of radiation-induced dysphagia involves various types of rehabilitation to improve the flow of the bolus and reduce aspiration risk. These include neuromuscular electrical stimulation and balloon dilatation [183], tongue, pharynx and larynx exercises [184], swallowing manoeuvres [175] acupuncture [185], postural techniques [186] and diet changes [173]. All were deemed to be effective in reducing dysphagia and improving QoL. Nevertheless, none of the previously mentioned were tested in large clinical trials, and their efficacity is questionable. In fact, a clinical trial investigating the role of acupuncture in radiation-mediated dysphagia is in progress in China [187]. An additional one in Toronto will assess the effectiveness of prophylactic swallowing exercises versus intervention exercises after the occurrence of dysphagia [188].

In contrast to dysphagia, limited studies address radiation-induced dysphonia. Non-laryngeal malignancies depending on their location can disturb voice quality, while laryngeal tumours will impede both voice and speech outcomes [189]. The expected short-term outcome could be an actual improvement in voice/speech due to shrinkage of the tumour if treatment is effective. Nevertheless, dysphonia can be the result of radiation-induced fibrosis and oedema of laryngeal structures and vocal folds. This is attributed to an increase in collagen and fibronectin deposits in the lamina propria [190, 191].

Some indicated speech deterioration after therapy $[179,192,193]$. Radiation impacted the strain, nasality, roughness and pitch aspects of patients' voices. The effect peaks at 10 weeks post-treatment, followed by gradual improvements that never reach pre-treatment levels [193]. Acute dysphonia culminates at 10 weeks post-RT followed by a subsequent downregulation that does not reach previous normal levels. The reported incidence of dysphonia varies between $10.5 \%$ and $64 \%$ depending on the assessment method and follow-up periods $[179,192,194]$. A dose to the larynx $>49.4$ Gy increases dysphonia risk in HNC patients [192]. Similar to previous neuropathies, IMRT alleviated dysphonia compared to conventional treatments [192, 194].

Pharmacological treatments aiming to abrogate inflammation and fibrosis of the larynx are used as first-line in treatment of dysphonia. The use of steroids, proton pump inhibitors and TNF-a have been advocated [195]. Moreover, cryotherapy promoted regeneration and reduced inflammation and fibrosis in larynxes of rabbits [196]. Thereafter, all of the abovementioned treatments should be investigated in radiationinduced dysphonia context.

Adequate hydration of the larynx has also been proposed, considering the damaging effect of radiation on laryngeal salivary glands and mucosa leading to vocal folds dryness $[195,197]$. In fact, Substance P, bombesin and enkephalin are upregulated in the innervation of these glands, suggesting a possible neurogenic root for voice impairment [198, 199]. Management of dysphonia includes non-pharmacological treatment modalities such as speech therapy. The latter aims to improve the flexibility of the larynx and to maximise phonation and articulation. Nonetheless, mixed data has been published regarding its effectiveness in treating speech impairments [195, 200-202]. In addition, multiple methods of surgical voice rehabilitation have been reported to ameliorate dysphonia in case reports [203, 204]. Recently, treating radiation-induced dysphonia with pulse dye laser has been the subject of a clinical trial in the United States [205].

\section{Conclusion}

Radiotherapy is undoubtedly one of the major contributors to managing HNC. Nevertheless, even with the most advanced radiation techniques, damage to neighbouring healthy tissues is inevitable. In this regard, radiation-induced neuropathy in HNC showed to be a multifactorial pathological process that takes many shapes depending on the treatment modality, anatomical location and patients' physiological conditions. Currently available medical options are modest in easing side effects, and preventive measures are successful to a certain extent. The potency and efficiency of drug-based findings should be interpreted in their ability to selectively radioprotect normal neuronal tissues while sparing tumours in HNC. Further research is urgently needed to mitigate and understand the different mechanisms underlying neural injuries following radiotherapy in HNC. In fact, current ongoing clinical trials tackling this subject are shy in numbers (table 1). ROS scavengers should be investigated as first-line radioprotective drugs. Several promising molecular venues can be further studied for mitigation of radiation neuropathies. For instance, a better knowledge of apoptotic and neuroinflammation pathways could shed light on encouraging 
Table 1. List of recent clinical trials involved in investigating approaches in managing radiation-induced neuropathies.

\begin{tabular}{|c|c|c|c|c|c|}
\hline Trial title & Identifier & Sponsor & Type of study & Primary treatment & Endpoint status \\
\hline $\begin{array}{l}\text { Gustatory Function Following Radio- } \\
\text { therapy in Head and Neck Cancer [1] }\end{array}$ & NCT03738657 & $\begin{array}{l}\text { Royal Marsden NHS } \\
\text { Foundation Trust }\end{array}$ & Cross-sectional & N/A & Recruiting \\
\hline $\begin{array}{l}\text { Efficacy of Zinc on Concurrent } \\
\text { Chemo-radiotherapy Induced Taste } \\
\text { Alterations [2] }\end{array}$ & NCT03824925 & $\begin{array}{l}\text { Dow University of } \\
\text { Health Sciences }\end{array}$ & $\begin{array}{l}\text { Double-blind randomised } \\
\text { controlled trial - Phase III }\end{array}$ & $\begin{array}{l}\text { *Placebo } \\
\text { *Zinc sulfate } 220 \mathrm{mg}\end{array}$ & Completed \\
\hline $\begin{array}{l}\text { Olfactory Training in Improving Sense } \\
\text { of Smell After Radiation Therapy in } \\
\text { Patients With Paranasal Sinus or } \\
\text { Nasopharyngeal Cancer [3] }\end{array}$ & NCT03049358 & Stanford University & $\begin{array}{l}\text { Single blinded randomised } \\
\text { trial - Phase I }\end{array}$ & *Olfactory training & Terminated \\
\hline $\begin{array}{l}\text { Effect and Safety of Apatinib on } \\
\text { Radiation-Induced Brain Injury [4] }\end{array}$ & NCT04152681 & $\begin{array}{l}\text { Sun Yat-Sen Memorial } \\
\text { Hospital of Sun Yat-Sen } \\
\text { University }\end{array}$ & $\begin{array}{l}\text { Single group assessment - } \\
\text { Phase II }\end{array}$ & *Apatinib $250 \mathrm{mg}$ & Recruiting \\
\hline $\begin{array}{l}\text { Stop LCNP: High Dose Steroid Thera- } \\
\text { py for Late Radiation-Associated } \\
\text { Lower Cranial Neuropathy [5] }\end{array}$ & NCT04151082 & $\begin{array}{l}\text { M.D. Anderson Cancer } \\
\text { Center }\end{array}$ & $\begin{array}{l}\text { Single group assessment - } \\
\text { Phase I/II }\end{array}$ & $\begin{array}{l}\text { *Methylprednisolone } \\
\text { *Prednisone }\end{array}$ & Recruiting \\
\hline $\begin{array}{l}\text { Study of Efficacy and Safety of } \\
\text { Gabapentin to Reduce the Need for } \\
\text { Strong Opioid Use in Head and Neck } \\
\text { Cancer Patients. (stREnGTH) [6] }\end{array}$ & NCT03747562 & $\begin{array}{l}\text { University Hospital, } \\
\text { Ghent }\end{array}$ & $\begin{array}{l}\text { Multi-center double- } \\
\text { blinded randomised } \\
\text { controlled trial - } \\
\text { Phase III } \\
\end{array}$ & $\begin{array}{l}\text { *Placebo } \\
\text { *Gabapentin } 100 \mathrm{mg}\end{array}$ & Not yet recruiting \\
\hline $\begin{array}{l}\text { Efficacy of Acupuncture in Radiother- } \\
\text { apy-induced Dysphagia in Patients } \\
\text { With Head and Neck Cancer [187] }\end{array}$ & NCT03336775 & $\begin{array}{l}\text { Sun Yat-Sen Memorial } \\
\text { Hospital of Sun Yat-Sen } \\
\text { Universit }\end{array}$ & $\begin{array}{l}\text { Single blinded randomized } \\
\text { trial }\end{array}$ & $\begin{array}{l}\text { *Acupuncture } \\
\text { *Methylprednisolone } \\
80 \mathrm{mg}\end{array}$ & Recruiting \\
\hline $\begin{array}{l}\text { PRO-ACTIVE: Prophylactic Swallow } \\
\text { Intervention for Patients Receiv- } \\
\text { ing Radiotherapy for Head and Neck } \\
\text { Cancer [188] }\end{array}$ & NCT03455608 & $\begin{array}{l}\text { University Health } \\
\text { Network, Toronto }\end{array}$ & Randomized & *Swallowing Training & Recruiting \\
\hline $\begin{array}{l}\text { Pulsed Dye Laser in Treating Patients } \\
\text { With Post Radiation Dysphonia [205] }\end{array}$ & NCT02198131 & $\begin{array}{l}\text { Wake Forest University } \\
\text { Health Sciences }\end{array}$ & Single group assessment & $\begin{array}{l}\text { *Pulse Dye Laser } \\
\text { Surgery }\end{array}$ & Completed \\
\hline
\end{tabular}

outlooks in halting neuronal damage. Although not discussed in this review, preclinical studies could focus on apprehending neurogenesis, as it might help in improving neuroregeneration in radiation-induced neuropathies. Future research should also benefit from previously established treatments for nerve injury models unrelated to radiation. The efficacity of these interventions ought to be investigated in managing neuropathies associated with RT in HNC under clinical trials.

\section{Conflicts of interest}

The authors declare no conflict of interest.

\section{Funding}

The current work has no funding support. 


\section{References}

1. Bray F, Ferlay J, and Soerjomataram I, et al (2018) Global cancer statistics 2018: GLOBOCAN estimates of incidence and mortality worldwide for 36 cancers in 185 countries CA Cancer J Clin 68(6) 394-424 https://doi.org/10.3322/caac.21492 PMID: 30207593

2. Minicucci EM, Da Silva GN, and Salvadori DMF (2014) Relationship between head and neck cancer therapy and some genetic endpoints World J Clin Oncol 5(2) 93-102 https://doi.org/10.5306/wjco.v5.i2.93 PMID: 24829856 PMCID: 4014801

3. Borras JM, Barton M, and Grau C, et al (2015) The impact of cancer incidence and stage on optimal utilization of radiotherapy: methodology of a population based analysis by the ESTRO-HERO project Radiother Oncol [Internet] 116(1) 45-50 https://doi. org/10.1016/j.radonc.2015.04.021 PMID: 26002304

4. Lumniczky K, Szatmári T, and Sáfrány G (2017) lonizing radiation-induced immune and inflammatory reactions in the brain Front Immunol 8(MAY) 1-13 https://doi.org/10.3389/fimmu.2017.00517

5. Scaravilli F, Love S, and Myers R (1986) X-irradiation impairs regeneration of peripheral nerve across a gap J Neurocytol 15(4) 439-449 https://doi.org/10.1007/BF01611727 PMID: 3746354

6. Kinsella TJ, Deluca AM, and Barnes M, et al (1991) Threshold dose for peripheral neuropathy following intraoperative radiotherapy (lort) in a large animal model Int J Radiat Oncol Biol Phys 20(September) 697-701 https://doi.org/10.1016/0360-3016(91)90011-R PMID: 2004946

7. Fishel ML, Vasko MR, and Kelley MR (2007) DNA repair in neurons: so if they don't divide what's to repair? Mutat Res - Fundam Mol Mech Mutagen 614(1-2) 24-36 https://doi.org/10.1016/j.mrfmmm.2006.06.007

8. Balentova S and Adamkov M (2015) Molecular, cellular and functional effects of radiation-induced brain injury: a review Int J Mol Sci 16(11) 27796-27815 https://doi.org/10.3390/ijms161126068 PMID: 26610477 PMCID: 4661926

9. Gobbel GT, Bellinzona M, and Vogt AR, et al (1998) Response of postmitotic neurons to x-irradiation: implications for the role of DNA damage in neuronal apoptosis J Neurosci 18(1) 147-155 https://doi.org/10.1523/JNEUROSCI.18-01-00147.1998 PMID: 9412495 PMCID: 6793394

10. Chien L, Chen WK, and Liu ST, et al (2015) Low-dose ionizing radiation induces mitochondrial fusion and increases expression of mitochondrial complexes I and III in hippocampal neurons Oncotarget 6(31) 30628-30639 https://doi.org/10.18632/oncotarget.5790 PMID: 26415228 PMCID: 4741557

11. Lu K, Zhang C, and Wu W, et al (2015) Rhubarb extract has a protective role against radiation-induced brain injury and neuronal cell apoptosis Mol Med Rep 12(2) 2689-2694 https://doi.org/10.3892/mmr.2015.3693 PMID: 25936269

12. Shabeeb D, Musa AE, and Keshavarz M, et al (2019) Histopathological and functional evaluation of radiation-induced sciatic nerve damage: melatonin as radioprotector Medicina 55(8) 1-12 https://doi.org/10.3390/medicina55080502

13. Zhang Y, Cheng Z, and Wang C, et al (2016) Neuroprotective effects of kukoamine a against radiation-induced rat brain injury through inhibition of oxidative stress and neuronal apoptosis Neurochem Res [Internet] 41(10) 2549-2558 https://doi.org/10.1007/s11064016-1967-0 PMID: 27241194

14. Tikka T, Usenius $T$, and Tenhunen M, et al (2001) Tetracycline derivatives and ceftriaxone, a cephalosporin antibiotic, protect neurons against apoptosis induced by ionizing radiation J Neurochem 78(6) 1409-1414 https://doi.org/10.1046/j.1471-4159.2001.00543.x PMID: 11579149

15. Saeed $\mathrm{Y}, \mathrm{Xie} B$, and $\mathrm{Xu} J$, et al (2014) Indirect effects of radiation induce apoptosis and neuroinflammation in neuronal SH-SY5Y cells Neurochem Res 39(12) 2334-2342 https://doi.org/10.1007/s11064-014-1432-x PMID: 25227747

16. Saeed Y, Xie B, and Xu J, et al (2015) Glial U87 cells protect neuronal SH-SY5Y cells from indirect effect of radiation by reducing oxidative stress and apoptosis Acta Biochim Biophys Sin (Shanghai) 47(4) 250-257 https://doi.org/10.1093/abbs/gmv004 
17. Noel F and Tofilon PJ (1998) Astrocytes protect against $\mathrm{x}$-ray-induced neuronal toxicity in vitro Neuroreport 9(6) 1133-1137 https:// doi.org/10.1097/00001756-199804200-00032 PMID: 9601681

18. Cai L, Iskander S, and Cherian MG, et al (2004) Zinc- or cadmium-pre-induced metallothionein protects human central nervous system cells and astrocytes from radiation-induced apoptosis Toxicol Lett 146(3) 217-226 https://doi.org/10.1016/j.toxlet.2003.09.013

19. Johnson MD, Xiang H, and London S, et al (1998) Evidence for involvement of Bax and p53, but not caspases, in radiationinduced cell death of cultured postnatal hippocampal neurons J Neurosci Res 54(6) 721-733 https://doi.org/10.1002/(SICl)10974547(19981215)54:6\&lt;721::AID-JNR1\&gt;3.0.CO;2-1 PMID: 9856857

20. Chong MJ, Murray MR, and Gosink EC, et al (2000) Atm and Bax cooperate in ionizing radiation-induced apoptosis in the central nervous system Proc Natl Acad Sci USA 97(2) 889-894 https://doi.org/10.1073/pnas.97.2.889 PMID: 10639175 PMCID: 15426

21. Hatanaka $\mathrm{H}$ and Enokido Y (1996) Involvement of ps3 in DNA strand break-induced apoptosis in postmitotic CNS neurons Biochem Soc Trans 24(4) 1812-1821 https://doi.org/10.1042/bst024604sa

22. Lee $\mathrm{Y}$ and McKinnon PJ (2000) ATM dependent apoptosis in the nervous system Apoptosis 5 523-529 https://doi. org/10.1023/A:1009637512917

23. Morrison RS and Kinoshita Y (2000) The role of p53 in neuronal cell death Cell Death Differ 7(10) 868-879 https://doi.org/10.1038/ sj.cdd. 4400741

24. Chow BM, Li Y, and Wong CS (2000) Radiation-induced apoptosis in the adult central nervous system is p53-dependent Cell Death Differ 7(8) 712-720 https://doi.org/10.1038/sj.cdd.4400704 PMID: 10918445

25. Casafont I, Palanca A, and Lafarga V, et al (2011) Effect of ionizing radiation in sensory ganglion neurons: organization and dynamics of nuclear compartments of DNA damage/repair and their relationship with transcription and cell cycle Acta Neuropathol 122(4) 481-493 https://doi.org/10.1007/s00401-011-0869-0 PMID: 21915754

26. Tong JX, Vogelbaum MA, and Drzymala RE, et al (1997) Radiation-induced apoptosis in dorsal root ganglion neurons J Neurocytol 26(11) 771-777 https://doi.org/10.1023/A:1018566431912

27. Tong J, Li J, and Zhang QS, et al (2018) Delayed cognitive deficits can be alleviated by calcium antagonist nimodipine by downregulation of apoptosis following whole brain radiotherapy Oncol Lett 16(2) 2525-2532 PMID: 30013647 PMCID: 6036595

28. Ferrer I (1996) Cell death in the normal developing brain, and following ionizing radiation, methyl-azoxymethanol acetate, and hypoxiaischaemia in the rat Neuropathol Appl Neurobiol 22(6) 489-494 https://doi.org/10.1111/j.1365-2990.1996.tb01121.x PMID: 9004234

29. Ferrer I, Olivé M, and Blanco R, et al (1996) Selective c-Jun overexpression is associated with ionizing radiation-induced apoptosis in the developing cerebellum of the rat Mol Brain Res 38(1) 91-100 https://doi.org/10.1016/0169-328X(95)00334-O PMID: 8737672

30. Zhang L, Huang P, and Chen $\mathrm{H}$, et al (2017) The inhibitory effect of minocycline on radiation-induced neuronal apoptosis via AMPKa1 signaling-mediated autophagy Sci Rep [Internet] 7(1) 1-16 https://doi.org/10.1038/s41598-017-16693-8

31. Thotala DK, Hallahan DE, and Yazlovitskaya EM (2012) Glycogen synthase kinase $3 \beta$ inhibitors protect hippocampal neurons from radiation-induced apoptosis by regulating MDM2-p53 pathway Cell Death Differ 19(3) 387-396 https://doi.org/10.1038/cdd.2011.94

32. Xu M, Fan Q, and Zhang J, et al (2017) NFAT3/c4-mediated excitotoxicity in hippocampal apoptosis during radiation-induced brain injury J Radiat Res 58(6) 827-833 https://doi.org/10.1093/jrr/rrx041 PMID: 28992110 PMCID: 5710526

33. Lee WH, Sonntag WE, and Mitschelen M, et al (2010) Irradiation induces regionally specific alterations in pro-inflammatory environments in rat brain Int J Radiat Biol 86(2) 132-144 https://doi.org/10.3109/09553000903419346 PMID: 20148699 PMCID: 2827151

34. Delanian S, Lefaix JL, and Pradat PF (2012) Radiation-induced neuropathy in cancer survivors Radiother Oncol [Internet] 105(3) 273-282 https://doi.org/10.1016/j.radonc.2012.10.012 PMID: 23245644 
35. Rutkowski MD, Winkelstein BA, and Hickey WF, et al (2002) Lumbar nerve root injury induces central nervous system neuroimmune activation and neuroinflammation in the rat: relationship to painful radiculopathy Spine (Phila Pa 1976) 27(15) 1604-1613 https://doi. org/10.1097/00007632-200208010-00003

36. Straub JM, New J, and Hamilton CD, et al (2016) Radiation-induced fibrosis: mechanisms and implications for therapy Radiation-induced Fibros Mech Implic Ther 141(11) 1-16

37. Greene-Schloesser DM, Moore E, and Robbins ME (2013) Molecular pathways: radiation-induced cognitive impairment Clin Cancer Res 19(9) 2294-2300 https://doi.org/10.1158/1078-0432.CCR-11-2903 PMID: 23388505 PMCID: 3642233

38. Sokolova IV, Schneider CJ, and Bezaire M, et al (2015) Proton radiation alters intrinsic and synaptic properties of ca1 pyramidal neurons of the mouse hippocampus Radiat Res 183(2) 208 https://doi.org/10.1667/RR13785.1 PMID: 25621896

39. Parihar VK and Limoli CL (2013) Cranial irradiation compromises neuronal architecture in the hippocampus Proc Natl Acad Sci USA 110(31) 12822-12877 https://doi.org/10.1073/pnas.1307301110 PMID: 23858442 PMCID: 3732939

40. Wu PH, Coultrap S, and Pinnix C, et al (2012) Radiation induces acute alterations in neuronal function PLoS One 7(5) 2-9

41. Rosi S, Andres-Mach M, and Fishman KM, et al (2008) Cranial irradiation alters the behaviorally induced immediate-early gene Arc (activity-regulated cytoskeleton-associated protein) Cancer Res 68(23) 9763-9770 https://doi.org/10.1158/0008-5472.CAN-08-1861 PMID: 19047155 PMCID: 2597278

42. Bellone JA, Rudobeck E, and Hartman RE, et al (2015) A single low dose of proton radiation induces long-term behavioral and electrophysiological changes in mice Radiat Res 184(2) 193-202 https://doi.org/10.1667/RR13903.1 PMID: 26207690

43. Kempf SJ, Moertl S, and Sepe S, et al (2014) Low-dose ionizing radiation rapidly a ff ects mitochondrial and synaptic signaling pathways in murine hippocampus and cortex J Proteome Res 14(5) 2055-2064 https://doi.org/10.1021/acs.jproteome.5b00114

44. Betlazar C, Middleton RJ, and Banati RB, et al (2016) The impact of high and low dose ionising radiation on the central nervous system Redox Biol [Internet] 9 144-156 https://doi.org/10.1016/j.redox.2016.08.002 PMID: 27544883 PMCID: 4993858

45. Leoncini E, Ricciardi W, and Cadoni G, et al (2014) Adult height and head and neck cancer: a pooled analysis within the INHANCE Consortium Head Neck 36(10) 1391

46. Mujica-Mota MA, Lehnert S, and Devic S, et al (2014) Mechanisms of radiation-induced sensorineural hearing loss and radioprotection Hear Res [Internet] 312 60-68 https://doi.org/10.1016/j.heares.2014.03.003 PMID: 24650954

47. Strojan P, Hutcheson KA, and Eisbruch A, et al (2017) Treatment of late sequelae after radiotherapy for head and neck cancer Cancer Treat Rev 59 79-92 https://doi.org/10.1016/j.ctrv.2017.07.003 PMID: 28759822 PMCID: 5902026

48. Bortfeld T (2006) IMRT: a review and preview Phys Med Biol 51(13) https://doi.org/10.1088/0031-9155/51/13/R21

49. Nutting CM, Morden JP, and Beasley M, et al (2018) Results of a multicentre randomised controlled trial of cochlear-sparing intensity-modulated radiotherapy versus conventional radiotherapy in patients with parotid cancer (COSTAR; CRUK/08/004) Eur J Cancer [Internet] 103(September 2017) 249-258 https://doi.org/10.1016/j.ejca.2018.08.006 PMID: 30286418 PMCID: 6202674

50. Low WK, Sun L, and Tan MGK, et al (2008) L-N-Acetylcysteine protects against radiation-induced apoptosis in a cochlear cell line Acta Otolaryngol 128(4) 440-445 https://doi.org/10.1080/00016480701762490 PMID: 18368580

51. Giese APJ, Guarnaschelli JG, and Ward JA, et al (2015) Radioprotective effect of aminothiol PrC-210 on irradiated inner ear of Guinea pig PLoS One 10(11) 1-11 https://doi.org/10.1371/journal.pone.0143606

52. Dinh C, Chen S, and Padgett K, et al (2015) Dexamethasone protects against radiation-induced loss of auditory hair cells in vitro Otol Neurotol 36(10) 1741-1747 https://doi.org/10.1097/MAO.0000000000000850 PMID: 26485588 
53. Pyun JH, Kang SU, and Hwang HS, et al (2011) Epicatechin inhibits radiation-induced auditory cell death by suppression of reactive oxygen species generation Neuroscience 199 410-420 https://doi.org/10.1016/j.neuroscience.2011.09.012 PMID: 21946009

54. Xie LH, Tang AZ, and Yin SH, et al (2012) Protective effects of n-acetylcysteine on cochlear damage occuring in guinea pigs exposed to irradiation Natl Med J China 92(14) 989-992

55. Mujica-Mota MA, Salehi P, and Devic S, et al (2014) Safety and otoprotection of metformin in radiation-induced sensorineural hearing loss in the guinea pig Otolaryngol - Head Neck Surg (United States) 150(5) 859-865 https://doi.org/10.1177/0194599814521013

56. Jin Y, Chen D, and Cabay RJ, et al (2013) Role of microRNA-138 as a potential tumor suppressor in head and neck squamous cell carcinoma [Internet] Vol. 303 Int Rev Cell Mol Biol 303 357-385 https://doi.org/10.1016/B978-0-12-407697-6.00009-X

57. Sheth S, Mukherjea D, and Rybak LP, et al (2017) Mechanisms of cisplatin-induced ototoxicity and otoprotection Front Cell Neurosci 11(October) 1-12 https://doi.org/10.3389/fncel.2017.00338

58. Hyppolito MA, De Oliveira JAA, and Miranda Lessa R, et al (2005) Otoproteção da amifostina aos efeitos otótoxicos da cisplatina: Estudo em cobaias albinas por emissões otoacústicas produtos de distorção e microscopia eletrônica de varredura Rev Bras Otorrinolaringol 71(3) 268-273 https://doi.org/10.1590/S0034-72992005000300002

59. Zuur CL, Simis YJ, and Lansdaal PE, et al (2007) Ototoxicity in a randomized phase III trial of intra-arterial compared with intravenous cisplatin chemoradiation in patients with locally advanced head and neck cancer J Clin Oncol 25(24) 3759-3765 https://doi.org/10.1200/ JCO.2006.08.9540 PMID: $\underline{17704425}$

60. Shorter P, Harden F, and Owen R, et al (2017) Risk profiles for sensorineural hearing loss in patients with head and neck cancer receiving cisplatin-based chemoradiation J Med Imaging Radiat Sci [Internet] 48(1) 61-67 https://doi.org/10.1016/j.jmir.2016.11.005 PMID: $\underline{31047212}$

61. Wong KL, Song TT, and Wee J, et al (2006) Sensorineural hearing loss after radiotherapy and chemoradiotherapy: a single, blinded, randomized study J Clin Oncol 24(12) 1904-1909 https://doi.org/10.1200/JCO.2005.05.0096

62. Gurney JG, Bass JK, and Onar-Thomas A, et al (2014) Evaluation of amifostine for protection against cisplatin-induced serious hearing loss in children treated for average-risk or high-risk medulloblastoma Neuro Oncol 16(6) 848-855 https://doi.org/10.1093/neuonc/ not241 PMID: 24414535 PMCID: 4022215

63. Fouladi M, Chintagumpala M, and Ashley D, et al (2008) Amifostine protects against cisplatin-induced ototoxicity in children with averagerisk medulloblastoma J Clin Oncol 26(22) 3749-3755 https://doi.org/10.1200/JCO.2007.14.3974 PMID: 18669462 PMCID: 2504739

64. Gu J, Zhu S, and Li X, et al (2014) Effect of amifostine in head and neck cancer patients treated with radiotherapy: a systematic review and meta-analysis based on randomized controlled trials PLoS One 9(5) https://doi.org/10.1371/journal.pone.0095968

65. Rybak LP, Mukherjea D, and Jajoo S, et al (2009) Cisplatin ototoxicity and protection: clinical and experimental studies Leonard Tohoku J Exp Med 219(3) 177-186 https://doi.org/10.1620/tjem.219.177 PMID: 19851045 PMCID: 2927105

66. Zhang Y, Chen D, and Zhao L, et al (2019) Nfatc4 deficiency attenuates ototoxicity by suppressing TNF-mediated hair cell apoptosis in the mouse cochlea Front Immunol 10(JULY) 1-11 https://doi.org/10.3389/fimmu.2019.01660

67. Spear SA and Schwartz SR (2011) Intratympanic steroids for sudden sensorineural hearing loss: a systematic review Otolaryngol - Head Neck Surg 145(4) 534-543 https://doi.org/10.1177/0194599811419466 PMID: 21873598

68. Formanek M, Czerny C, and Gstoettner W, et al (1998) Cochlear implantation as a successful rehabilitation for radiation-induced deafness Eur Arch Oto-Rhino-Laryngol 255(4) 175-178 https://doi.org/10.1007/s004050050038

69. Eryigit B, Ziylan F, and Yaz F, et al (2018) The effectiveness of hyperbaric oxygen in patients with idiopathic sudden sensorineural hearing loss: a systematic review Eur Arch Oto-Rhino-Laryngol [Internet] 275(12):2893-904 https://doi.org/10.1007/s00405-018-5162-6 
70. Chaudhari N and Roper SD The cell biology of taste J Cell Biol 190(3) 285-296 PMID: 20696704 PMCID: 2922655

71. Mossman K, Shatzman A, and Chencharick J (1982) Long-term effects of radiotherapy on taste and salivary function in man Int J Radiat Oncol Biol Phys 8(6) 991-997 https://doi.org/10.1016/0360-3016(82)90166-3 PMID: 7107441

72. Schwartz LK, Weiffenbach JM, and Valdez IH, et al (1993) Taste intensity performance in patients irradiated to the head and neck Physiol Behav 53(4) 671-677 https://doi.org/10.1016/0031-9384(93)90172-C PMID: 8511171

73. Epstein JB and Barasch A (2010) Taste disorders in cancer patients: Pathogenesis, and approach to assessment and management Oral Oncol [Internet] 46(2) 77-81 https://doi.org/10.1016/j.oraloncology.2009.11.008

74. Irune E, Dwivedi RC, and Nutting CM, et al (2014) Treatment-related dysgeusia in head and neck cancer patients Cancer Treat Rev [Internet] 40(9) 1106-1117 https://doi.org/10.1016/j.ctrv.2014.06.011 PMID: 25064135

75. Barbosa da Silva JL, Doty RL, and Miyazaki JVMK, et al (2019) Gustatory disturbances occur in patients with head and neck cancer who undergo radiotherapy not directed to the oral cavity Oral Oncol 95(June) 115-119 https://doi.org/10.1016/j.oraloncology.2019.06.008 PMID: 31345378

76. Barbosa da Silva JL, Doty RL, and Miyazaki JVMK, et al (2019) Gustatory disturbances occur in patients with head and neck cancer who undergo radiotherapy not directed to the oral cavity Oral Oncol [Internet] 95(May) 115-119 https://doi.org/10.1016/j.oraloncology.2019.06.008 PMID: 31345378

77. Spotten LE, Corish CA, and Lorton CM, et al (2017) Subjective and objective taste and smell changes in cancer Ann Oncol Off J Eur Soc Med Oncol 28(5) 969-984 https://doi.org/10.1093/annonc/mdx018

78. Deshpande TS, Blanchard P, and Wang L, et al (2018) Radiation-related alterations of taste function in patients with head and neck cancer: a systematic review Curr Treat Options Oncol 19(12) https://doi.org/10.1007/s11864-018-0580-7 PMID: 30411162 PMCID: 6244914

79. Maes A, Huygh I, and Weltens C, et al (2002) De Gustibus: Time scale of loss and recovery of tastes caused by radiotherapy Radiother Oncol 63(2) 195-201 https://doi.org/10.1016/S0167-8140(02)00025-7 PMID: 12063009

80. Sapir E, Tao Y, and Feng F, et al (2016) Predictors of dysgeusia in patients with oropharyngeal cancer treated with chemotherapy and intensity modulated radiation therapy Int J Radiat Oncol Biol Phys [Internet] 96(2) 354-361 https://doi.org/10.1016/j.ijrobp.2016.05.011 PMID: 27473816

81. Sandow PL, Hejrat-Yazdi M, and Heft MW (2006) Taste loss and recovery following radiation therapy J Dent Res 85(7) 608-611 https:// doi.org/10.1177/154405910608500705 PMID: 16798859

82. Fang FM, Chien CY, and Tsai WL, et al (2008) Quality of life and survival outcome for patients with nasopharyngeal carcinoma receiving three-dimensional conformal radiotherapy vs. intensity-modulated radiotherapy-a longitudinal study Int J Radiat Oncol Biol Phys 72(2) 356-364 https://doi.org/10.1016/j.ijrobp.2007.12.054 PMID: 18355980

83. NCT03049358 (2020) Gustatory Function Following Radiotherapy to the Head and Neck https://clinicaltrials.gov/ct2/show/ NCT03049358

84. Jewkes BC, Barlow LA, and Delay ER (2018) Effect of radiation on sucrose detection thresholds of mice Chem Senses 43(1) 53-58 https://doi.org/10.1093/chemse/bjx066 PMCID: $\underline{5863550}$

85. Gaillard D, Shechtman LA, and Millar SE, et al (2019) Fractionated head and neck irradiation impacts taste progenitors, differentiated taste cells, and Wnt/ $\beta$-catenin signaling in adult mice Sci Rep 9(1) 17934 https://doi.org/10.1038/s41598-019-54216-9 PMID: 31784592 PMCID: 6884601

86. Nguyen HM, Reyland ME, and Barlow LA (2012) Mechanisms of taste bud cell loss after head and neck irradiation J Neurosci 32(10) 3474-3484 https://doi.org/10.1523/JNEUROSCI.4167-11.2012 PMID: 22399770 PMCID: 3320161 
87. Guo Q, Chen S, and Rao X, et al (2019) Inhibition of SIRT1 promotes taste bud stem cell survival and mitigates radiation-induced oral mucositis in mice Am J Transl Res 11(8) 4789-4799 PMID: 31497199 PMCID: 6731402

88. Yuan Z, Ma J, and Meng X, et al (2018) Chk2 deficiency alleviates irradiation-induced taste dysfunction by inhibiting p53-dependent apoptosis Oral Dis 24(5) 856-863 https://doi.org/10.1111/odi.12822 PMID: 29292572

89. Ripamonti C, Zecca E, and Brunelli C, et al (1998) A randomized, controlled clinical trial to evaluate the effects of zinc sulfate on cancer patients with taste alterations caused by head and neck irradiation Cancer 82(10) 1938-1945 https://doi.org/10.1002/(SICI)10970142(19980515)82:10\&lt;1938::AID-CNCR18\&gt;3.0.CO;2-U PMID: 9587128

90. Halyard MY, Jatoi A, and Sloan JA, et al (2007) Does zinc sulfate prevent therapy-induced taste alterations in head and neck cancer patients? results of phase iii double-blind, placebo-controlled trial from the North Central Cancer Treatment Group (N01C4) Int J Radiat Oncol Biol Phys 67(5) 1318-1322 https://doi.org/10.1016/j.jjrobp.2006.10.046 PMID: 17394940

91. Khan AH, Safdar J, and Siddiqui SU (2019) Efficacy of zinc sulfate on concurrent chemoradiotherapinduced taste alterations in oral cancer patients: A double blind randomized controlled trial Pakistan J Med Sci [Internet] 35(3) 624-629 http://www.embase.com/search/ results?subaction=viewrecord\&from=export\&id=L2002299181\%0Ahttp://dx.doi.org/10.12669/pjms.35.3.503

92. NCT03824925 (2020) Efficacy of Zinc on Concurrent Chemo-radiotherapy Induced Taste Alterations [Internet] https://clinicaltrials. gov/show/NCT03824925 https://www.cochranelibrary.com/central/doi/10.1002/central/CN-01919003/full

93. Hovan AJ, Williams PM, and Stevenson-Moore P, et al (2010) A systematic review of dysgeusia induced by cancer therapies Support Care Cancer 18(8) 1081-1087 https://doi.org/10.1007/s00520-010-0902-1 PMID: 20495984

94. Jang MH, Piao XL, and Kim JM, et al (2008) Inhibition of cholinesterase and amyloid-\&bgr; aggregation by resveratrol oligomers from Vitis amurensis Phyther Res [Internet] 22(4) 544-549 http://www3.interscience.wiley.com/journal/117934759/abstract https://doi. org/10.1002/ptr.2406

95. Sharma A, Haksar A, and Chawla R, et al (2005) Zingiber officinale Rosc. modulates gamma radiation-induced conditioned taste aversion Pharmacol Biochem Behav 81(4) 864-870 https://doi.org/10.1016/j.pbb.2005.06.012 PMID: 16023187

96. Ansa B, Goodman M, and Ward K, et al (2013) Paranasal sinus squamous cell carcinoma incidence and survival based on surveillance, epidemiology, and end results data, 1973 to 2009 Cancer 119(14) 2602-2610 https://doi.org/10.1002/cncr.28108 PMID: 23674262

97. Schwob JE (2002) Neural regeneration and the peripheral olfactory system Anat Rec 269(1) 33-49 https://doi.org/10.1002/ar.10047 PMID: 11891623

98. Sroussi HY, Epstein JB, and Bensadoun RJ, et al (2017) Common oral complications of head and neck cancer radiation therapy: mucositis, infections, saliva change, fibrosis, sensory dysfunctions, dental caries, periodontal disease, and osteoradionecrosis Cancer Med 6(12) 2918-2931 https://doi.org/10.1002/cam4.1221 PMID: 29071801 PMCID: 5727249

99. Álvarez-Camacho M, Gonella S, and Campbell S, et al (2017) A systematic review of smell alterations after radiotherapy for head and neck cancer Cancer Treat Rev [Internet] 54 110-121 https://doi.org/10.1016/j.ctrv.2017.02.003 PMID: 28242521

100.Riva G, Raimondo L, and Ravera M, et al (2015) Late sensorial alterations in different radiotherapy techniques for nasopharyngeal cancer Chem Senses 40(4) 285-292 https://doi.org/10.1093/chemse/bjv011 PMID: 25800268

101.Wang JJ, Liang KL, and Twu CW, et al (2015) Olfactory change after intensity-modulated radiotherapy for nasopharyngeal carcinoma Int Forum Allergy Rhinol 5(11) 1059-1062 https://doi.org/10.1002/alr.21575 PMID: 26077632

102.Su Y-x, Liu L-p, and Li L, et al (2014) Factors influencing the incidence of sinusitis in nasopharyngeal carcinoma patients after intensitymodulated radiation therapy Eur Arch Oto-Rhino-Laryngol 271(12) 3195-3201 https://doi.org/10.1007/s00405-014-3004-8

103.Cunha C, Hort Y, and Shine J, et al (2012) Morphological and behavioural changes occur following the X-ray irradiation of the adult mouse olfactory neuroepithelium BMC Neurosci 13(1) https://doi.org/10.1186/1471-2202-13-134 PMID: 23113950 PMCID: 3536589 
104.Díaz D, Muñoz-Castañeda R, and Ávila-Zarza C, et al (2017) Olfactory bulb plasticity ensures proper olfaction after severe impairment in postnatal neurogenesis Sci Rep 7(1) 1-13 https://doi.org/10.1038/s41598-017-05970-1

105.NCT03049358 (2017) Olfactory training in improving sense of smell after radiation therapy in patients with paranasal sinus or nasopharyngeal cancer https://clinicaltrials.gov/ct2/show/NCT03049358

106.Fleiner F, Lau L, and Göktas Ö (2012) Active olfactory training for the treatment of smelling disorders Ear, Nose Throat J 91(5) 198-215 https://doi.org/10.1177/014556131209100508

107.Hummel T, Reden KRJ, and Hähner A, et al (2009) Effects of olfactory Training in patients with olfactory loss Laryngoscope 119(3) 496-499 https://doi.org/10.1002/lary.20101 PMID: 19235739

108.Damm M, Pikart LK, and Reimann $\mathrm{H}$, et al (2014) Olfactory training is helpful in postinfectious olfactory loss: a randomized, controlled, multicenter study Laryngoscope 124(4) 826-831 https://doi.org/10.1002/lary.24340

109.Leopold D (2002) Distortion of olfactory perception: diagnosis and treatment Chem Senses 27(7) 611-615 https://doi.org/10.1093/ chemse/27.7.611 PMID: 12200340

110. Heilmann S, Huettenbrink KB, and Hummel T (2004) Local and systemic administration of corticosteroids in the treatment of olfactory loss Am J Rhinol 18(1) 29-33 https://doi.org/10.1177/194589240401800107 PMID: 15035568

111.Michael W (2003) Anosmia treated with acupuncture Acupunct Med 21(4) 153-154 https://doi.org/10.1136/aim.21.4.153

112.Wen-Ping Z and Ishida T (2006) An ageusia and dysosmia patient treated by acupuncture Chin J Integr Med 12(1) 66-67 https://doi. org/10.1007/BF02857436

113. Henkin RI, Potolicchio SJ, and Levy LM (2011) Improvement in smell and taste dysfunction after repetitive transcranial magnetic stimulation Am J Otolaryngol - Head Neck Med Surg [Internet] 32(1) 38-46 https://doi.org/10.1016/j.amjoto.2009.10.001

114.Quint C, Temmel AFP, and Hummel T, et al (2002) The quinoxaline derivative caroverine in the treatment of sensorineural smell disorders: a proof-of-concept study Acta Otolaryngol 122(8) 877-881 https://doi.org/10.1080/003655402_000028054

115. Gökalp O, Yeşilkaya NK, and Beşir Y, et al (2016) Effects of pentoxifylline on blood transfusion Anatol J Cardiol 16(3) 226 PMID: 27067574 PMCID: $\underline{5336826}$

116. Henkin RI, Schultz M, and Minnick-Poppe L (2012) Intranasal theophylline treatment of hyposmia and hypogeusia: a pilot study Arch Otolaryngol - Head Neck Surg 138(11) 1064-1070 https://doi.org/10.1001/2013.jamaoto.342 PMID: 23165381

117.Reden J, Lill K, and Zahnert T, et al (2012) Olfactory function in patients with postinfectious and posttraumatic smell disorders before and after treatment with vitamin A: A double-blind, placebo-controlled, randomized clinical trial Laryngoscope 122(9) 1906-1909 https://doi.org/10.1002/lary.23405 PMID: 22752966

118. Hummel T, Heilmann S, and Hüttenbriuk KB (2002) Lipoic acid in the treatment of smell dysfunction following viral infection of the upper respiratory tract Laryngoscope 112(11) 2076-2080 https://doi.org/10.1097/00005537-200211000-00031 PMID: 12439184

119.Reden J, Herting B, and Lill K, et al (2011) Treatment of postinfectious olfactory disorders with minocycline: a double-blind, placebocontrolled study Laryngoscope 121(3) 679-682 https://doi.org/10.1002/lary.21401 PMID: 21287560

120.Aiba T, Sugiura M, and Mori J, et al (1998) Effect of zinc sulfate on sensorineural olfactory disorder Acta Oto-Laryngologica, Suppl (538) 202-204

121.Epstein JB, Wilkie DJ, and Fischer DJ, et al (2009) Neuropathic and nociceptive pain in head and neck cancer patients receiving radiation therapy Head Neck Oncol 126 https://doi.org/10.1186/1758-3284-1-26 PMID: 19594943 PMCID: 2717963

122.Vasić L (2007) Radiation-induced peripheral neuropathies: Etiopathogenesis, risk factors, differential diagnostics, symptoms and treatment Arch Oncol 15(3-4) 81-84 https://doi.org/10.2298/A000704081V 
123.Chen AM, Hall WH, and Li J, et al (2012) Brachial plexus-associated neuropathy after high-dose radiation therapy for head-and-neck cancer Int J Radiat Oncol Biol Phys [Internet] 84(1) 165-169 https://doi.org/10.1016/j.ijrobp.2011.11.019 PMID: 22444998

124.Platteaux N, Dirix P, and Hermans R, et al (2010) Brachial plexopathy after chemoradiotherapy for head and neck squamous cell carcinoma Strahlentherapie und Onkol 186(9) 517-520 https://doi.org/10.1007/s00066-010-2099-0

125. Metcalfe E and Etiz D (2016) Early transient radiation-induced brachial plexopathy in locally advanced head and neck cancer Wspolczesna Onkol 20(1) 67-72 https://doi.org/10.5114/wo.2015.55876

126. Thomas TO, Refaat T, and Choi M, et al (2015) Brachial plexus dose tolerance in head and neck cancer patients treated with sequential intensity modulated radiation therapy Radiat Oncol [Internet] 10(1) 1-8 https://doi.org/10.1186/s13014-015-0409-5

127. Yan M, Kong W, and Kerr A, et al (2019) The radiation dose tolerance of the brachial plexus: a systematic review and meta-analysis Clin Transl Radiat Oncol [Internet] 18 23-31 https://doi.org/10.1016/j.ctro.2019.06.006 PMID: 31309161 PMCID: 6606964

128.Dong Y, Ridge JA, and Ebersole B, et al (2019) Incidence and outcomes of radiation-induced late cranial neuropathy in 10-year survivors of head and neck cancer Oral Oncol 95(May) 59-64 https://doi.org/10.1016/j.oraloncology.2019.05.014 PMID: 31345395

129. Hutcheson KA, Yuk M, and Hubbard R, et al (2017) Delayed lower cranial neuropathy after oropharyngeal imrt: a cohort analysis and literature review 39(8) 1516-1523 https://doi.org/10.1002/hed.24789 PMID: 28452175 PMCID: 5511776

130.Janssen S, Glanzmann C, and Yousefi B, et al (2015) Radiation-induced lower cranial nerve palsy in patients with head and neck carcinoma Mol Clin Oncol 3(4) 811-816 https://doi.org/10.3892/mco.2015.558 PMID: 26171186 PMCID: 4487065

131.Luk YS, Shum JSF, and Sze HCK, et al (2013) Predictive factors and radiological features of radiation-induced cranial nerve palsy in patients with nasopharyngeal carcinoma following radical radiotherapy Oral Oncol 49(1) 49-54 https://doi.org/10.1016/j.oraloncology.2012.07.011

132.Berger PS and Bataini JP (1977) Radiation-induced cranial nerve palsy Cancer 40(1) 152-155 https://doi.org/10.1002/10970142(197707)40:1\&lt;152::AID-CNCR2820400125\&gt;3.0.CO;2-E PMID: 195702

133. Lin YS, Jen YM, and Lin JC (2002) Radiation-related cranial nerve palsy in patients with nasopharyngeal carcinoma Cancer 95(2) 404-409 https://doi.org/10.1002/cncr.10668 PMID: 12124841

134.Rong X, Tang Y, and Chen M, et al (2012) Radiation-induced cranial neuropathy in patients with nasopharyngeal carcinoma: a follow-up study Strahlentherapie und Onkol 188(3) 282-286 https://doi.org/10.1007/s00066-011-0047-2

135. Kong L, Lu JJ, and Liss AL, et al (2011) Radiation-induced cranial nerve palsy: A cross-sectional study of nasopharyngeal cancer patients after definitive radiotherapy Int J Radiat Oncol Biol Phys 79(5) 1421-1427 https://doi.org/10.1016/j.jjrobp.2010.01.002

136. Li JC, Mayr NA, and Yuh WTC, et al (2006) Cranial nerve involvement in nasopharyngeal carcinoma: response to radiotherapy and its clinical impact Ann Otol Rhinol Laryngol 115(5) 340-345 https://doi.org/10.1177/000348940611500504 PMID: 16739664

137. Yi SK, Hall WH, and Mathai M, et al (2012) Validating the RTOG-endorsed brachial plexus contouring atlas: an evaluation of reproducibility among patients treated by intensity-modulated radiotherapy for head-and-neck cancer Int J Radiat Oncol Biol Phys 82(3) 1060-1064 https://doi.org/10.1016/j.jprobp.2010.10.035

138. Truong MT, Nadgir RN, and Hirsch AE, et al (2010) Brachial plexus contouring with CT and MR imaging in radiation therapy planning for head and neck cancer Radiographics 30(4) 1095-1103 https://doi.org/10.1148/rg.304095105 PMID: 20631370

139.Chang JTC, Lin CY, and Chen TM, et al (2005) Nasopharyngeal carcinoma with cranial nerve palsy: the importance of MRI for radiotherapy Int J Radiat Oncol Biol Phys 63(5) 1354-1360 https://doi.org/10.1016/j.ijrobp.2005.05.042 PMID: 16297716

140.Mourad WF, Young BM, and Young R, et al (2013) Clinical validation and applications for CT-based atlas for contouring the lower cranial nerves for head and neck cancer radiation therapy Oral Oncol 49(9) 956-963 https://doi.org/10.1016/j.oraloncology.2013.03.449 PMID: 23623404 
141.Ko HC, Gupta V, and Mourad WF, et al (2014) A contouring guide for head and neck cancers with perineural invasion Pract Radiat Oncol [Internet] 4(6) E247-E258 https://doi.org/10.1016/j.prro.2014.02.001

142.NCT04152681 (2019) Effect and Safety of Apatinib on Radiation-Induced Brain Injury https://www.cochranelibrary.com/central/ doi/10.1002/central/CN-01919003/full

143.NCT04151082 (2020) Stop LCNP: high dose steroid therapy for late radiation-associated lower cranial neuropathy https://clinicaltrials. gov/ct2/show/NCT04151082

144.NCT03747562 (2020) Study of efficacy and safety of gabapentin to reduce the need for strong opioid use in head and neck cancer patients https://clinicaltrials.gov/ct2/show/NCT03747562

145.Smart D (2017) Radiation toxicity in the central nervous system: mechanisms and strategies for injury Reduction Semin Radiat Oncol 27(4) 332-339 https://doi.org/10.1016/j.semradonc.2017.04.006 PMID: 28865516 PMCID: 5657507

146.Sakellariou VI, Badilas NK, and Stavropoulos NA, et al (2014) Treatment options for brachial plexus injuries ISRN Orthop 2014 1-10

147.Jiang J, Li Y, and Shen Q, et al (2019) Effect of pregabalin on radiotherapy-related neuropathic pain in patients with head and neck cancer: a randomized controlled trial J Clin Oncol 37(2) 135-143 https://doi.org/10.1200/JCO.18.00896

148. Pritchard J, Anand P, and Broome J, et al (2001) Double-blind randomized phase II study of hyperbaric oxygen in patients with radiation-induced brachial plexopathy Radiother Oncol 58(3) 279-286 https://doi.org/10.1016/S0167-8140(00)00319-4 PMID: 11230889

149.Delanian S, Chatel C, and Porcher R, et al (2011) Complete restoration of refractory mandibular osteoradionecrosis by prolonged treatment with a pentoxifylline-tocopherol-clodronate combination (PENTOCLO): a phase II trial Int J Radiat Oncol Biol Phys 80(3) 832-839 https://doi.org/10.1016/j.jijrobp.2010.03.029

150. Rubin DI, Schomberg PJ, and Shepherd RFJ, et al (2001) Arteritis and brachial plexus neuropathy as delayed complications of radiation therapy Mayo Clin Proc 76(8) 849-852 https://doi.org/10.1016/S0025-6196(11)63232-1 PMID: 11499827

151.Ozkaya Akagunduz O, Guven Yilmaz S, and Yalman D, et al (2017) Evaluation of the radiation dose-volume effects of optic nerves and chiasm by psychophysical, electrophysiologic tests, and optical coherence tomography in nasopharyngeal carcinoma Technol Cancer Res Treat 16(6) 969-977 https://doi.org/10.1177/1533034617711613 PMID: 28585489 PMCID: 5762056

152.Awaguchi OSK, No TAU, and Akano HIT, et al (1999) Late retinal complications of radiation therapy for nasal and paranasal malignancies : relationship between irradiated-dose area and severity Radiat Oncol 44(3) 599-605

153.Demizu Y, Murakami M, and Miyawaki D, et al (2009) Analysis of vision loss caused by radiation-induced optic neuropathy after particle therapy for head-and-neck and skull-base tumors adjacent to optic nerves Int J Radiat Oncol Biol Phys 75(5) 1487-1492 https://doi. org/10.1016/j.jijobp.2008.12.068 PMID: 19345516

154. Monroe AT, Bhandare N, and Morris CG, et al (2005) Preventing radiation retinopathy with hyperfractionation Int J Radiat Oncol Biol Phys 61(3) 856-864 https://doi.org/10.1016/j.ijrobp.2004.07.664 PMID: 15708266

155.Bhandare N, Monroe AT, and Morris CG, et al (2005) Does altered fractionation influence the risk of radiation-induced optic neuropathy? Int J Radiat Oncol Biol Phys 62(4) 1070-1077 PMID: 15990010

156.Miller NR (2004) Radiation-induced optic neuropathy: still no treatment Clin Exp Ophthalmol 32(3) 233-235 https://doi.org/10.1111/ j.1442-9071.2004.00809.x PMID: 15180831

157. Higginson DS, Sahgal A, and Lawrence MV, et al (2013) External beam radiotherapy for head and neck cancers is associated with increased variability in retinal vascular oxygenation PLoS One 8(8) https://doi.org/10.1371/journal.pone.0069657

158.Borges HL, Chao C, and Xu Y, et al (2004) Radiation-induced apoptosis in developing mouse retina exhibits dose-dependent requirement for ATM phosphorylation of p53 Cell Death Differ 11(5) 494-502 https://doi.org/10.1038/sj.cdd.4401366 PMID: 14752509 
159. Ryu S, Kolozsvary A, and Jenrow KA, et al (2007) Mitigation of radiation-induced optic neuropathy in rats by ACE inhibitor ramipril: importance of ramipril dose and treatment time J Neurooncol 82(2) 119-124 https://doi.org/10.1007/s11060-006-9256-4

160. Yang J, Li Q, and Han D, et al (2020) Radiation-induced impairment of optic nerve axonal transport in tree shrews and rats monitored by longitudinal manganese-enhanced MRI Neurotoxicology [Internet] 77(October 2019) 145-154 https://doi.org/10.1016/j. neuro.2020.01.008 PMID: 31987859

161.Finger PT and Chin KJ (2012) Antivascular endothelial growth factor bevacizumab for radiation optic neuropathy: secondary to plaque radiotherapy Int J Radiat Oncol Biol Phys 82(2) 789-798 https://doi.org/10.1016/j.jjrobp.2010.11.075

162.Finger PT (2006) Anti-VEGF Bevacizumab (Avastin $®)$ for radiation optic neuropathy Br Rep 143(2) 335-338

163.Sherman JH, Aregawi DG, and Lai A, et al (2009) Optic neuropathy in patients with glioblastoma receiving bevacizumab Neurology 73 1924-1926 https://doi.org/10.1212/WNL.0b013e3181c3fd00 PMID: 19949039 PMCID: 2796439

164. Roden D, Bosley TM, and Fowble B, et al (1990) Delayed radiation injury to the retrobulbar optic nerves and chiasm: clinical syndrome and treatment with hyperbaric oxygen and corticosteroids Ophthalmology [Internet] 97(3) 346-351 https://doi.org/10.1016/S01616420(90)32582-4 PMID: 2336273

165.Malik A and Golnik K (2012) Hyperbaric oxygen therapy in the treatment of radiation optic neuropathy J Neuro-Ophthalmol 32(2) 128-131 https://doi.org/10.1097/WNO.0b013e3182464c88

166.Borruat FX, Schatz NJ, and Glaser JS, et al (1993) Visual recovery from radiation-induced optic neuropathy: the role of hyperbaric oxygen therapy J Clin Neuroophthalmol 13(2) 98-101 PMID: 8340486

167. Farooq O, Lincoff NS, and Saikali N, et al (2012) Novel treatment for radiation optic neuropathy with intravenous bevacizumab J NeuroOphthalmol 32(4) 321-324 https://doi.org/10.1097/WNO.0b013e3182607381

168. Chahal HS, Lam A, and Khaderi SK (2013) Is pentoxifylline plus vitamin E an effective treatment for radiation-induced optic neuropathy? J Neuro-Ophthalmol 33(1) 91-93 https://doi.org/10.1097/WNO.0b013e318276d4b8

169.Gupta P, Meisenberg B, and Amin P, et al (2001) Radiation retinopathy: the role of pentoxifylline Retina 21(5) 545-547 https://doi. org/10.1097/00006982-200110000-00026 PMID: 11642393

170.Weintraub JA, Bennett J, and Gaspar LE (2011) Successful treatment of radiation-induced optic neuropathy Pract Radiat Oncol [Internet] 1(1) 40-44 https://doi.org/10.1016/j.prro.2010.09.004 PMID: 24673869

171.Langmore SE and Krisciunas GP (2010) Dysphagia after radiotherapy for head and neck cancer: etiology, clinical presentation, and efficacy of current treatments Perspect Swallowing Swallowing Disord 19(2) 32-38 https://doi.org/10.1044/sasd19.2.32

172.Manikantan K, Khode S, and Sayed SI, et al (2009) Dysphagia in head and neck cancer Cancer Treat Rev [Internet] 35(8) 724-732 https:// doi.org/10.1016/j.ctrv.2009.08.008 PMID: 19751966

173. Murphy BA and Gilbert J (2009) Dysphagia in head and neck cancer patients treated with radiation: assessment, sequelae, and rehabilitation Semin Radiat Oncol [Internet] 19(1) 35-42 https://doi.org/10.1016/j.semradonc.2008.09.007

174.Nguyen NP, Moltz CC, and Frank C, et al (2004) Dysphagia following chemoradiation for locally advanced head and neck cancer Ann Oncol 15(3) 383-388 https://doi.org/10.1093/annonc/mdh101 PMID: 14998839

175.Platteaux N, Dirix P, and Dejaeger E, et al (2019) Dysphagia in head and neck cancer patients treated with chemoradiotherapy Dysphagia 25(2) 139-152 https://doi.org/10.1007/s00455-009-9247-7

176.King SN, Dunlap NE, and Tennant PA, et al (2016) Pathophysiology of radiation-induced dysphagia in head and neck cancer Dysphagia 31(3) 339-351 https://doi.org/10.1007/s00455-016-9710-1 PMID: 27098922 PMCID: 5340192 
177.Rinkel RN, Verdonck-de Leeuw IM, and Doornaert P, et al (2016) Prevalence of swallowing and speech problems in daily life after chemoradiation for head and neck cancer based on cut-off scores of the patient-reported outcome measures SWAL-QOL and SHI Eur Arch Oto-Rhino-Laryngol 273(7) 1849-1855 https://doi.org/10.1007/s00405-015-3680-z

178. Mortensen HR, Jensen K, and Aksglæde K, et al (2013) Late dysphagia after IMRT for head and neck cancer and correlation with dosevolume parameters Radiother Oncol [Internet] 107(3) 288-294 https://doi.org/10.1016/j.radonc.2013.06.001 PMID: 23791365

179. Heijnen BJ, Speyer R, and Kertscher B, et al (2016) Dysphagia, speech, voice, and trismus following radiotherapy and/or chemotherapy in patients with head and neck carcinoma: review of the literature Biomed Res Int 2016 https://doi.org/10.1155/2016/6086894 PMID: 27722170 PMCID: 5045989

180.Alterio D, Gerardi MA, and Cella L, et al (2017) Radiation-induced acute dysphagia. Prospective observational study on 42 head and neck cancer patients Strahlentherapie und Onkol 193(11) 971-981 https://doi.org/10.1007/s00066-017-1206-x

181.Eisbruch A, Schwartz M, and Rasch C, et al (2004) Dysphagia and aspiration after chemoradiotherapy for head-and-neck cancer: which anatomic structures are affected and can they be spared by IMRT? Int J Radiat Oncol Biol Phys 60(5) 1425-1439 https://doi. org/10.1016/j.jijrobp.2004.05.050 PMID: 15590174

182.Feng FY, Kim HM, and Lyden TH, et al (2007) Intensity-modulated radiotherapy of head and neck cancer aiming to reduce dysphagia: early dose-effect relationships for the swallowing structures Int J Radiat Oncol Biol Phys 68(5) 1289-1298 https://doi.org/10.1016/j. ijrobp.2007.02.049 PMID: 17560051

183. Long Y Bin, Wu XP. A randomized controlled trail of combination therapy of neuromuscular electrical stimulation and balloon dilatation in the treatment of radiation-induced dysphagia in nasopharyngeal carcinoma patients Disabil Rehabil 35(6) 450-454 PMID: 22762238

184.Tang Y, Shen Q, and Wang Y, et al (2011) A randomized prospective study of rehabilitation therapy in the treatment of radiationinduced dysphagia and trismus Strahlentherapie und Onkol 187(1) 39-44 https://doi.org/10.1007/s00066-010-2151-0

185.Lu W, Posner MR, and Wayne P, et al (2010) Acupuncture for dysphagia after chemoradiation therapy in head and beck cancer: a case series report Integr Cancer Ther 9(3) 284-290 https://doi.org/10.1177/1534735410378856 PMID: 20713374 PMCID: 3014053

186. Logemann JA, Rademaker AW, and Pauloski BR, et al (1994) Effects of postural change on aspiration in head and neck surgical patients Otolaryngol Neck Surg 110(2) 222-227 https://doi.org/10.1177/019459989411000212

187.NCT03336775 (2020) Efficacy of acupuncture in radiotherapy-induced dysphagia in patients with head and neck cancer https://clinicaltrials.gov/ct2/show/NCT03336775

188.NCT03455608 (2020) PRO-ACTIVE: prophylactic swallow intervention for patients receiving radiotherapy for head and neck cancer NCT03455608 https://clinicaltrials.gov/ct2/show/NCT03455608

189.Jacobi I, Van Der Molen L, and Huiskens H, et al (2010) Voice and speech outcomes of chemoradiation for advanced head and neck cancer: a systematic review Eur Arch Oto-Rhino-Laryngol 267(10) 1495-1505 https://doi.org/10.1007/s00405-010-1316-X

190.Johns MM, Kolachala V, and Berg E, et al (2012) Radiation fibrosis of the vocal fold: from man to mouse Laryngoscope 122 107-125 https://doi.org/10.1002/lary.23735

191.Berg EE, Kolachala V, and Branski RC, et al (2011) Pathologic effects of external-beam irradiation on human vocal folds Ann Otol Rhinol Laryngol [Internet] 120(11) 748-754 file://G:/nikhila thesis/thesis references/voice assessment/article5.htm https://doi. org/10.1177/000348941112001109

192.Sanguineti G, Ricchetti F, and McNutt T, et al (2014) Dosimetric predictors of dysphonia after intensity-modulated radiotherapy for oropharyngeal carcinoma Clin Oncol 26(1) 32-38 https://doi.org/10.1016/j.clon.2013.08.006 
193. Van Der Molen L, Van Rossum MA, and Jacobi I, et al (2012) Pre- and posttreatment voice and speech outcomes in patients with advanced head and neck cancer treated with chemoradiotherapy: Expert listeners' and patient's perception $J$ Voice [Internet] 26(5) 664.e25-664.e33 https://doi.org/10.1016/j.jvoice.2011.08.016

194. Kraaijenga SAC, Oskam IM, and Van Son RJJH, et al (2016) Assessment of voice, speech, and related quality of life in advanced head and neck cancer patients 10-years+ after chemoradiotherapy Oral Oncol [Internet] 55 24-30 https://doi.org/10.1016/j.oraloncology.2016.02.001 PMID: 26874554

195.Villari CR and Courey MS (2015) Management of dysphonia after radiation therapy Otolaryngol Clin North Am 48(4) 601-609 https:// doi.org/10.1016/j.otc.2015.04.006 PMID: 26092762

196.Gong T, Zhang C, and Kang J, et al (2019) The effects of cryotherapy on vocal fold healing in a rabbit model Laryngoscope 129(4) E151E157 https://doi.org/10.1002/lary.27629

197.Lazarus CL (2009) Effects of chemoradiotherapy on voice and swallowing Curr Opin Otolaryngol Head Neck Surg 17(3) 172-178 https:// doi.org/10.1097/MO0.0b013e32832af12f PMID: 19337126 PMCID: 2745635

198. Lidegran M, Domeij S, and Dahlqvist $\AA$, et al (1995) Irradiation influences the expression of substance $P$ and enkephalin in the rat larynx Cell Tissue Res 279(1) 55-63 https://doi.org/10.1007/BF00300691 PMID: 7534650

199.Lidegran M, Forsgren S, and Dahlqvist $\AA$, et al (1999) Short- and long-term effects of irradiation on laryngeal mucosa of the rat Acta Oncol (Madr) 38(8) 1081-1091 https://doi.org/10.1080/028418699432400

200.Tuomi L, Andréll P, and Finizia C (2014) Effects of voice rehabilitation after radiation therapy for laryngeal cancer: a randomized controlled study Int J Radiat Oncol Biol Phys 89(5) 964-972 https://doi.org/10.1016/j.ijrobp.2014.04.030 PMID: 25035200

201.Taito M, Taito S, and Banno M, et al (2019) Voice rehabilitation for laryngeal cancer after radiotherapy: a systematic review and metaanalysis Eur Arch Oto-Rhino-Laryngol 276(6) 1573-1583 https://doi.org/10.1007/s00405-019-05452-2

202.Van Gogh CDL, Verdonck-De Leeuw IM, and Boon-Kamma BA, et al (2006) The efficacy of voice therapy in patients after treatment for early glottic carcinoma Cancer 106(1) 95-105 https://doi.org/10.1002/cncr.21578

203.Sittel C, Zorowka P, and Friedrich G, et al (2002) Surgical voice rehabilitation after laser surgery for glottic carcinoma Ann Otol Rhinol Laryngol 111(6) 493-499 https://doi.org/10.1177/000348940211100604 PMID: 12090704

204.Shah RR, Weinstein GS, and Mirza NA (2019) Voice restoration after radiation and supracricoid partial laryngectomy by injection augmentation of the arytenoid J Voice [Internet] 1-4 https://doi.org/10.1016/j.jvoice.2019.11.002

205.NCT02198131 (2020) Pulsed dye laser in treating patients with post radiation dysphonia https://www.clinicaltrials.gov/ct2/show/ NCT02198131 